\title{
Monitoring the lowermost tropospheric ozone with thermal infrared observations from a geostationary platform: performance analyses for a future dedicated instrument
}

\author{
P. Sellitto ${ }^{1, *}$, G. Dufour ${ }^{1}$, M. Eremenko ${ }^{1}$, J. Cuesta ${ }^{1}$, G. Forêt ${ }^{1}$, B. Gaubert ${ }^{1}$, M. Beekmann ${ }^{1}$, V.-H. Peuch ${ }^{2}$, and \\ J.-M. Flaud ${ }^{1}$ \\ ${ }^{1}$ Laboratoire Inter-universitaire des Systèmes Atmosphériques, UMR7583, CNRS - Universités Paris-Est et Paris Diderot, \\ CNRS, 61 Avenue du Général de Gaulle, 94010 Créteil, France \\ ${ }^{2}$ European Centre for Medium-Range Weather Forecasts (ECMWF), Research Department, Shinfield Park, Reading, \\ Berkshire, RG2 9AX, UK \\ "now at: Laboratoire de Météorologie Dynamique, UMR8539, CNRS - École Normale Supérieure, 24 Rue Lhomond, 75231, \\ Paris, France
}

Correspondence to: P. Sellitto (psellitto@1md.ens.fr)

Received: 28 May 2013 - Published in Atmos. Meas. Tech. Discuss.: 15 July 2013

Revised: 20 December 2013 - Accepted: 4 January 2014 - Published: 6 February 2014

\begin{abstract}
In this paper, we present performance analyses for a concept geostationary observing system called MAGEAQ (Monitoring the Atmosphere from Geostationary orbit for European Air Quality). The MAGEAQ mission is designed to include a TIR (thermal infrared) spectrometer and a broadband VIS (visible) radiometer; in this work we study only the TIR component (MAGEAQ-TIR). We have produced about 20 days of MAGEAQ-TIR tropospheric ozone pseudoobservations with a full forward and inverse radiative transfer pseudo-observations simulator. We have studied the expected sensitivity of MAGEAQ-TIR and we have found that it is able to provide a full single piece of information for the ozone column from surface to $6 \mathrm{~km}$ (about 1.0 DOF (degrees of freedom) and maximum sensitivity at about $3.0 \mathrm{~km}$, on average), as well as a partially independent surface $-3 \mathrm{~km}$ ozone column (about 0.6 DOF and maximum sensitivity at about $2.5 \mathrm{~km}$, on average). Then, we have compared the tropospheric ozone profiles and the lower (surface- $6 \mathrm{~km}$ ) and lowermost (surface- $3 \mathrm{~km}$ ) tropospheric ozone column pseudoobservations to the target pseudo-reality, produced with the MOCAGE (MOdèle de Chimie Atmosphérique à Grande Echelle) chemistry and transport model. We have found very small to not significant average biases $(<1 \%$ in absolute value, for the surface- $6 \mathrm{~km}$ TOC (tropospheric ozone column), and about -2 to $-3 \%$, for the surface $-3 \mathrm{~km}$ TOC)
\end{abstract}

and small RMSEs (root mean square errors; about 1.3 DU $(5 \%)$, for the surface- $6 \mathrm{~km}$ TOC, and about $1.5 \mathrm{DU}(10 \%)$, for the surface $-3 \mathrm{~km}$ TOC). We have tested the performance of MAGEAQ-TIR at some selected small $\left(0.2^{\circ} \times 0.2^{\circ}\right)$ urban and rural locations. We have found that, while the vertical structures of the lower tropospheric ozone pseudoreality are sometimes missed, MAGEAQ-TIR's lower and lowermost column pseudo-observations follow stunningly good the MOCAGE column pseudo-reality, with correlation coefficients reaching values of 0.9 or higher. Unprecedented retrieval performance for the lowermost tropospheric ozone column is shown. In any case, our MAGEAQ-TIR pseudo-observations are only partially able to replicate the MOCAGE pseudo-reality variability and temporal cycle at the very lowest layers (surface and $1 \mathrm{~km}$ altitude), especially at southern European urban locations, where the photochemistry signal is partially missed or shifted at higher altitudes. Temporal artifacts on the daily cycle are sometimes observed. Stratospheric-to-tropospheric exchanges during short time periods (of the order of 1 day) are detected by the MAGEAQ-TIR pseudo-observations. 


\section{Introduction}

The ozone is an important tropospheric constituent due of its threefold effect. First, it is a greenhouse gas in the upper troposphere (Shindell et al., 2009). Second, it is a precursor of the hydroxyl radical, and thus it can modulate the oxidising capacity of the troposphere (Fuglestved et al., 2011). Finally, it is a secondary pollutant at the lowest altitudes, where it can adversely interact with the biosphere and human health (Amann et al., 2005). Tropospheric ozone is formed with photochemical reactions involving carbon monoxide, methane and other volatile organic compounds in the presence of nitrogen oxides and sunlight (Derwent et al., 1996) or it is imported from the stratosphere due to stratospheretroposphere exchanges (STEs) (Hsu and Prather, 2009). Due to its role as a pollutant, the ozone concentration in the lower troposphere is one of the most important atmospheric variables for air quality (AQ) monitoring (WMO, 2007).

The short-term variability (of the order of hours) of the ozone concentrations in the lowermost (here defined as altitudes lower than $3 \mathrm{~km}$ ) troposphere can be significant, due to the heterogeneity of the sources and sinks of ozone precursors at the lowest altitudes, as well as transportation and mixing processes. Satellite observations of tropospheric ozone provide a valuable complement to in situ measurements and atmospheric modelling to draw a more comprehensive picture of pollution processes that can have a relevant impact on the biosphere (The Integrated Global Atmospheric Chemistry Observation Theme Team, 2004). Monitoring AQ-relevant variables, as the lower tropospheric ozone concentrations, from space is of a great importance (Martin, 2008). Currently, the tropospheric ozone information is derived from nadir satellite instruments flying in a low Earth orbit (LEO), exploiting different spectral bands and multispectral approaches, such as the ultraviolet (e.g. Fishman and Larsen, 1987; Munro et al., 1998; Ziemke et al., 2003; Liu et al., 2005, 2010; Schoeberl et al., 2007; Sellitto et al., 2011; Di Noia et al., 2013), the synergy ultraviolet/visible (UV/VIS) (Sellitto et al., 2012a, b), the thermal infrared (TIR) (e.g. Worden et al., 2007a; Eremenko et al., 2008), and the synergy UV/TIR (Fu et al., 2013; Cuesta et al., 2013). The complementarity of the observations from space, with respect to in situ measurements, lies in their dense spatial sampling. The drawbacks are a generally scarce sensitivity at the lowest altitudes and a limited revisit time. Satellite instruments flying in a LEO orbit and operating in the TIR spectral range, like IASI (Infrared Atmospheric Sounder Interferometer) (Eremenko et al., 2008; Boynard et al., 2009; Dufour et al., 2010, 2012) or TES (Tropospheric Emission Spectrometer) (Bowman et al., 2006; Worden et al., 2007a; Osterman et al., 2008) are regarded as more sensitive to lower tropospheric ozone than present UV/VIS instruments. They are able to provide the tropospheric ozone information with up to about 1-2 degrees of freedom (DOF) and a total error of $8-14 \%$ in the troposphere, and up to $0.6 \mathrm{DOF}$ and a total error of $10-16 \%$ in the lower troposphere (surface$6 \mathrm{~km}$ ) (Dufour et al., 2012). The consequence is that it is not possible, in general, to obtain a full single piece of information on the lower tropospheric ozone, except when in favourable conditions, e.g. with high positive thermal contrasts (Dufour et al., 2010). In addition, a LEO orbit cannot provide a sufficient time sampling to observe phenomena occurring at subdaily to hourly timescales. To this aim, a better choice would be a geostationary Earth orbit (GEO) observing system, whose revisit time is of the order of hours. Space agencies worldwide have recently started the planning of GEO missions dedicated to AQ monitoring, using both TIR and UV/VIS instruments. The final goal is to have a constellation of GEO observing systems, to monitor both the local to continental, and the transcontinental processes, with a high temporal sampling, in a coordinated manner (Atmospheric Composition Constellation, 2011). The GEO-CAPE (GEOstationary Coastal and Air Pollution Events) (Natraj et al., 2011; Fishman et al., 2012), which has recently been recommended for launch in an intermediate time frame by the US National Research Council, is planned to observe the lowermost tropospheric ozone over North America. In the concept of GEO-CAPE, the high sensitivity at the lower tropospheric ozone is achieved by using high spectral resolution/low radiometric noise TIR and UV/VIS dedicated instruments and their synergy (Natraj et al., 2011). Similar missions are planned in Japan and Korea (Atmospheric Composition Constellation, 2011). On the contrary, existing and planned GEO TIR missions over Europe, e.g. the MTG-IRS (Meteosat Third Generation-InfraRed Sounder) (Stuhlmann et al., 2005), the TIR component of the more complex and multi-spectral MTG mission, may not be well adapted for this task. The IRS's primary science objective is the observation of meteorological parameters. The MTG mission is completed with the UVN (ultraviolet-visible-near infrared) (Bazalgette Courrèges-Lacoste et al., 2011). A synergistic approach UV/VIS/TIR is considered as beneficial to gain a better sensitivity on the ozone in the lower troposphere (e.g. Worden et al., 2007b; Cuesta et al., 2013). In any case, the instrumental characterisation of IRS may not be well adapted to exploit the maximum information in the TIR to complement with UVN. IRS is expected to have a spectral resolution of $0.625 \mathrm{~cm}^{-1}$, in terms of the spectral sampling interval, and a radiometric noise of $24.5 \mathrm{nW}\left(\mathrm{cm}^{2} \mathrm{srcm}\right)^{-1}$, in terms of noise equivalent spectral radiance, and a pixel size of about $4 \mathrm{~km}$. This may bring a lack of high quality lower tropospheric ozone observations over Europe. To fill this gap, different concept GEO TIR observing systems, specifically aimed to AQ monitoring, have been proposed in the past, see e.g. Burrows et al. (2004); Flaud et al. (2004), but never been selected for funding.

Here we show a group of simulation exercises to evaluate the performance of a concept GEO mission dedicated to air quality monitoring over Europe, in the TIR spectral region, namely the MAGEAQ (Monitoring the Atmosphere 
from Geostationary orbit for European Air Quality) (Peuch et al., 2010; Lahoz et al., 2012; Claeyman et al., 2011b). It should be noted that MAGEAQ is expected to include also a broadband visible radiometer. In our study, we analyse the performance of the TIR component only from the MAGEAQ mission (hereafter mentioned as MAGEAQ-TIR). MAGEAQ has been a candidate for the ESA's (European Space Agency) Earth Explorer 8 call for proposals (Peuch et al., 2010), but not selected. Due to the high spectral resolution and signalto-noise ratio in the ozone TIR band near $10 \mu \mathrm{m}$, MAGEAQTIR is expected to be well adapted to retrieve the lower tropospheric ozone information, and then to better complement the MTG-UVN, with respect to IRS. A first comparison of the MAGEAQ-TIR and an IRS-like instrument performance for lower tropospheric ozone monitoring has been performed by Claeyman et al. (2011b). In comparison with Claeyman et al. (2011b), our study is based on a full direct and inverse radiative transfer modelling, based on a state-of-the-art inversion algorithm, optimised for lower tropospheric ozone retrievals (Eremenko et al., 2008). In addition, we have done a more detailed simulation of the observation geometry of MAGEAQTIR. We provide a statistical characterisation of the lower tropospheric ozone sensitivity of the MAGEAQ-TIR and of the a posteriori retrieval error, and a height-resolved analysis of the MAGEAQ-TIR performance.

In Sect. 2 we describe the data set produced for this study and the simulator used to generate the MAGEAQ-TIR pseudo-observations. In Sects. 3 and 4 we assess the vertical sensitivity and the accuracy of the MAGEAQ-TIR pseudoobservations. In Sect. 5 we study how MAGEAQ-TIR can reproduce the temporal variations of the ozone columns and in Sect. 6 we investigate how it is able to reproduce the vertical distribution of the ozone pseudo-reality. In Sect. 7 we conclude to which degree this observing system will improve the capability to monitor short-term pollution phenomena at the local and continental scales in Europe.

\section{Data sets description}

\subsection{Instrument configuration: the MAGEAQ-TIR instrument}

The pseudo-observations simulator described by Sellitto et al. (2013) is adapted to simulate the MAGEAQ observing system. MAGEAQ is a concept, multi-spectral geostationary observing system, which has been proposed in response to the call for proposals for Earth Explorer opportunity mission EE-8 (Peuch et al., 2010; Claeyman et al., 2011a, b; Lahoz et al., 2012). MAGEAQ is a GEO payload, specifically designed for AQ monitoring over Europe. Its primary scientific goal is to provide high frequency observations of tropospheric ozone and carbon monoxide, with a significant sensitivity to the lowermost troposphere. The lowermost tropospheric ozone is observed by means of a TIR
Fourier transform spectrometer and a broadband VIS radiometer. This latter is intended to complement the TIR spectrometer by giving surface information. In our work, only the TIR component of the MAGEAQ mission is considered. We consider the outcomes of the phase 0 study carried out by EADS (European Aeronautic Defence and Space Company)-Astrium and the MAGEAQ Science Team (Peuch et al., 2010), and we set up our simulations accordingly. A high spectral resolution, with spectral sampling interval of $0.05 \mathrm{~cm}^{-1}$, and a small radiometric noise, with noise equivalent spectral radiance of $6.04 \mathrm{nW}\left(\mathrm{cm}^{2} \mathrm{srcm}\right)^{-1}$ (3 times better than, e.g. IASI) are here considered. It has been evaluated that this instrumental configuration is well adapted to AQ monitoring in terms of the lowermost tropospheric ozone (Claeyman et al., 2011a, b). Table 1 displays the main specifications of the phase 0 threshold and target configuration of MAGEAQ-TIR (from Peuch et al., 2010). As for the observation geometry, we have considered the phase 0 threshold configuration of MAGEAQ-TIR, i.e. a horizontal resolution of $15 \mathrm{~km} \times 15 \mathrm{~km}$ at subsatellite point, a subsatellite point at latitude $=0$ and longitude $=0$, and a field of regard of $15^{\circ} \mathrm{W}-35^{\circ} \mathrm{E}, 35^{\circ} \mathrm{N}-65^{\circ} \mathrm{N}$. In the present work we do not simulate the variation of the pixel dimension and geometry for different lines of sight, but we use the same resolution of $15 \mathrm{~km} \times 15 \mathrm{~km}$ over the whole field of regard. It should be noted that previous performance assessments of MAGEAQ-TIR have been performed on the coarser grid of the nature run (Claeyman et al., 2011a, b). We have simulated an hourly revisit time (so, the phase 0 target configuration of MAGEAQ-TIR) for the period 5-28 August 2009. Please note that, in the subsequent analyses, some hourly data are missing due to failure in our data processing system.

\subsection{Pseudo-observations simulator}

We have produced MAGEAQ-TIR pseudo-observations with the modular simulator used by Sellitto et al. (2013) to simulate the IASI and IASI-NG (New Generation) observing systems. The only change with respect to the set-up described in this work is the definition of the observing system's technical specification, observing geometry and revisit time. Our pseudo-observations simulator provides full forward and inverse radiative transfer calculations, based on the KOPRA (Karlsruhe Optimized and Precise Radiative transfer Algorithm) radiative transfer model (RTM) (Stiller et al., 2002). It must be noted that the set-up of our pseudo-observations simulator has an intrinsic simplification with respect to real observations. In fact, performing the forward and inverse radiative modelling with the same RTM, thus incorporating the same physics, eliminates the systematic forward model errors, which must be taken into account when dealing with real observations.

The pseudo-reality (or nature run) is produced by means of the MOCAGE (MOdèle de Chimie Atmosphérique à Grande Echelle) chemistry and transport model (CTM) (Dufour 
Table 1. Selected phase 0 threshold and target technical specifications of MAGEAQ-TIR (adapted from Peuch et al., 2010). In the table, SSP: subsatellite point.

\begin{tabular}{lll}
\hline & Threshold & Target \\
\hline Lifetime & \multicolumn{2}{c}{$5 \mathrm{yr}$} \\
Field of regard & \multicolumn{2}{c}{$15^{\circ} \mathrm{W}-35^{\circ} \mathrm{E}, 35^{\circ} \mathrm{N}-65^{\circ} \mathrm{N}$} \\
Spatial sampling at SSP & $15 \mathrm{~km} \times 15 \mathrm{~km}$ & $10 \mathrm{~km} \times 10 \mathrm{~km}$ \\
Repeat cycle & $2 \mathrm{~h}$ & $1 \mathrm{~h}$ \\
DOF in the troposphere & 2 & 3 \\
\hline
\end{tabular}

et al., 2005). The MOCAGE CTM simulates physical and chemical processes affecting the main chemical species in the troposphere and the stratosphere. MOCAGE uses the RACMOBUS chemical scheme, which is a combination of the REPROBUS (Lefèvre et al., 1994) and the RACM scheme (Stockwell et al., 1997). The horizontal grid of the MOCAGE simulations is $0.2^{\circ} \times 0.2^{\circ}$ over Europe. It produces outputs as trace gas vertical concentration profiles at 47 hybrid vertical levels (from the surface up to about $35 \mathrm{~km}$ ), with a vertical resolution of about $200 \mathrm{~m}$ into the lower troposphere, and up to about $1 \mathrm{~km}$ into the stratosphere. MOCAGE trace gas outputs have been validated in the past with fourdimensional observations, e.g. Dufour et al. (2005) and during measurement campaigns, e.g. Bousserez et al. (2007). We have used a run of MOCAGE for the period 5-28 August 2009. The profiles have been completed with fixed, typically representative trace gas profiles for the altitude range between about 35 and $65 \mathrm{~km}$.

The outputs of MOCAGE are then resampled (interpolated) at a coarser vertical grid, $1 \mathrm{~km}$ in the troposphere and lower stratosphere, up to $2-5 \mathrm{~km}$ at higher altitudes, as required for the subsequent radiative transfer calculation. The forward radiative transfer is simulated by means of the KOPRA RTM, which takes as inputs the MOCAGE pseudo-reality and gives as outputs the radiance spectra as observed by the selected observing system. The simulated spectra are finally inverted by means of the KOPRAfit module (Hoepfner et al., 2001), to obtain the ozone profile pseudo-observations, at $1 \mathrm{~km}$ vertical resolution. Our inversion scheme is based on an existing altitude-dependent Tikhonov-Phillips regularisation method, which, as well, uses the KOPRA RTM. This algorithm, which has been developed to invert IASI radiance spectra measurements, is thoroughly described by Eremenko et al. (2008). The constraint matrix $\mathbf{R}$ is a combination of the identity matrix $\mathbf{L}_{0}$, first- and second-derivative operators $\mathbf{L}_{1}$ and $\mathbf{L}_{2}$, with coefficients $\alpha_{0}, \alpha_{1}$ and $\alpha_{2}$ depending on the altitude:

$\mathbf{R}=\alpha_{0}(z) \mathbf{L}_{0} \mathbf{L}_{0}^{T}+\alpha_{1}(z) \mathbf{L}_{1} \mathbf{L}_{1}^{T}+\alpha_{2}(z) \mathbf{L}_{2} \mathbf{L}_{2}^{T}$.

The coefficients $\alpha_{0}, \alpha_{1}$ and $\alpha_{2}$ are optimised to obtain a compromise between the maximisation of the sensitivity in the lower troposphere and a minimisation of the retrieved profile error. In our simulations, we have used the same spectral microwindows used by, e.g. Eremenko et al. (2008) with real IASI measurements. The inversion algorithm operates at seven spectral microwindows, in the region of 975$1100 \mathrm{~cm}^{-1}$, to avoid carbon dioxide and water vapour impact on ozone retrievals. The KOPRAfit also provides the averaging kernels (AKs) that are used to characterise the vertical sensitivity of the retrievals. It must be kept in mind that the $1 \mathrm{~km}$ vertical resolution of the output is finer than the actual vertical resolution of the simulated instrument, as it will be shown in Sect. 3. The AKs are then a necessary tool to interpret the retrieved profiles, in terms of their vertical sensitivity. McPeters climatology (McPeters et al., 2007) is used for the a priori information. As done by Sellitto et al. (2013), we have used two different ozone a priori profiles, depending on the tropopause altitude, to limit numerical instability and aberrant oscillations in the solutions. We have considered tropopauses higher than $14 \mathrm{~km}$ as a proxy for tropical air masses. Consequently, the ozone a priori profile, in these cases, has been chosen as a tropical a priori (yearly climatological profile $20-30^{\circ} \mathrm{N}$, from McPeters climatology). For pixels with tropopauses lower than $14 \mathrm{~km}$, a midlatitude a priori is used (summer climatological profile $30-60^{\circ} \mathrm{N}$, from McPeters climatology). Other parameters, like temperature profiles and emissivity, are not retrieved and are taken fixed from the pseudo-reality.

Finally, more than 20 days of MAGEAQ-TIR pseudoobservations, with $1 \mathrm{~h}$ revisit time, are produced in the region of interest. The number of the processed pixels is about 15 million. The complete direct and inverse radiative transfer calculations, which need a significant computation effort, have been performed by means of the European Grid Infrastructure (EGI)-France Grilles supercomputing platform (Eremenko et al., 2012). As done by Sellitto et al. (2013), the effect of clouds is not considered in the present study. This choice has been made to maximise the statistical population with the available simulated data set. Please note that in Claeyman et al. (2011a, b) a cloud mask has been used.

\section{Vertical resolution and lowermost tropospheric ozone sensitivity}

Figure 1 shows the rows of the averaging kernel matrix, or the AKs, for a typical simulation (observation over land, $+1 \mathrm{~K}$ thermal contrast, 10:00 UTC, Coordinated Universal Time). AKs for the first 12 altitude levels, thus spanning the troposphere, are reported. Each AK gives the vertical sensitivity of the retrieval at a given level to the target profile. Two to three peaks of sensitivity in the troposphere can be seen, at about $2-3 \mathrm{~km}, 6-8 \mathrm{~km}$ and $10-12 \mathrm{~km}$.

Two useful diagnostic parameters for the evaluation of the vertical sensitivity of satellite retrievals are the DOF and the altitude of the maximum sensitivity. Both parameters can be calculated from the averaging kernel (AK) matrix. The DOF are the number of independent pieces of information that can 


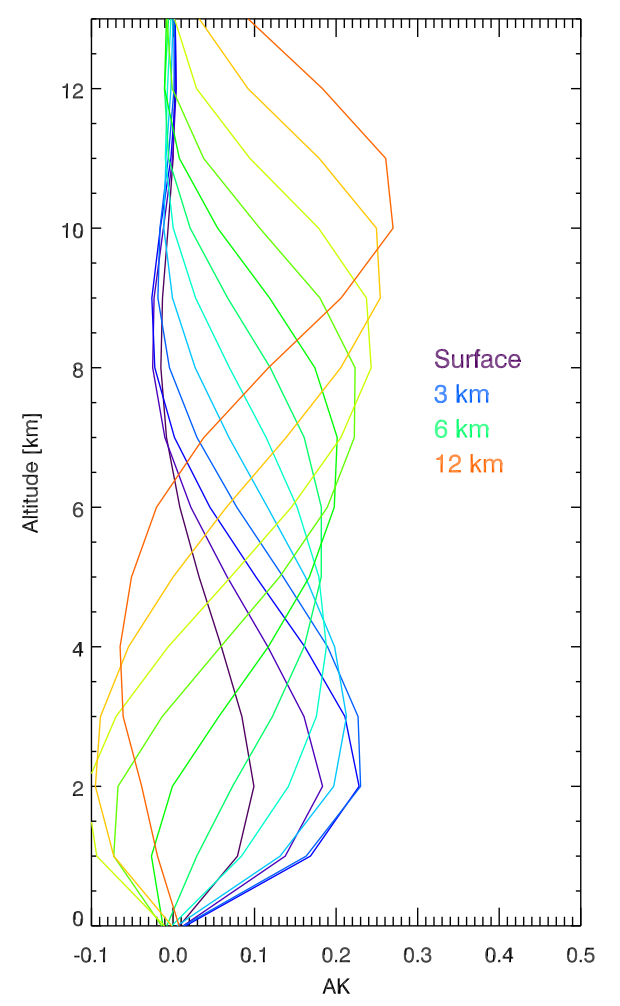

Fig. 1. Averaging kernels from surface to $12 \mathrm{~km}$ for a single typical ozone profile MAGEAQ-TIR pseudo-observation (see text for details).

be obtained from an observation. The DOF for a partial column are calculated as the trace of the AK matrix, up to the top height of the column. The altitude of the maximum sensitivity of a partial column observation can be estimated by calculating the altitude of the maximum of the integrated $\mathbf{A K}$ for that partial column. Here we concentrate on the tropospheric ozone partial columns up to 6 and $3 \mathrm{~km}$, hereafter referred to as surface- $3 \mathrm{~km}$ TOC (tropospheric ozone column) and surface- $6 \mathrm{~km}$ TOC.

Figure 2 shows the histograms of the DOF for surface$6 \mathrm{~km}$ and surface $-3 \mathrm{~km}$, and of the altitudes of the maximum sensitivity of the surface- $6 \mathrm{~km}$ and the surface $-3 \mathrm{~km}$ TOCs. The histograms are obtained by considering all observations in our data set. The mean value and the standard deviation of the distributions are also reported in the figure. Our simulations show that an instrument like MAGEAQ-TIR would be able to retrieve the surface- $6 \mathrm{~km}$ ozone column with more than 1.0 DOF, on average, and a maximum sensitivity at about $3.0 \mathrm{~km}$, so at the centre of the nominal column, which indeed means that the information on the lower tropospheric ozone would be independent on ozone concentrations at higher altitudes. In addition, these results show that the MAGEAQ-TIR measurements also have a significant sensitivity to the surface- $3 \mathrm{~km}$ TOC, with 0.57 DOF on average, and a peak of sensitivity at about $2.5 \mathrm{~km}$.
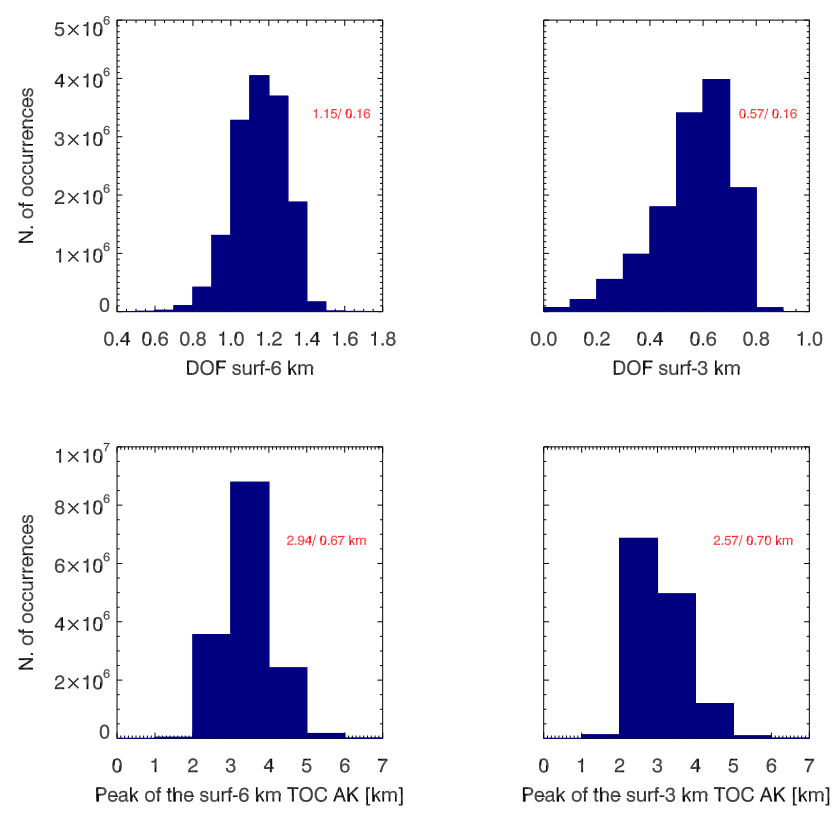

Fig. 2. Histograms of the DOF for surface-6 km (top left), the DOF for surface- $3 \mathrm{~km}$ (top right), the altitudes of the maximum of the integrated AK for the surface- $6 \mathrm{~km}$ TOC (bottom left), and the altitudes of the maximum of the integrated AK for the surface- $3 \mathrm{~km}$ TOC (bottom right), for MAGEAQ-TIR. Mean values and standard deviations are also reported in red (mean/SD). The data cover the whole period of study, on a $1 \mathrm{~h}$ revisit time basis.

To further investigate the sensitivity of the MAGEAQTIR observations, we have studied the DOFs and the peaks of sensitivity for a number of different situations. We have then partitioned our data set into different subsets: day and night observations, and land and sea pixels. Observations during daytime hours (hereafter referred to as the DT subset) are those taken in the interval 08:00-19:00 UTC and, conversely, observations during night time hours (hereafter referred to as the NT subset) are those taken in the interval 20:00-07:00 UTC. Tables 2 and 3 summarise the mean values of the DOFs for surface- $6 \mathrm{~km}$ and surface $-3 \mathrm{~km}$, and the altitude of the peak of the sensitivity for the surface- $6 \mathrm{~km}$ and surface- $3 \mathrm{~km}$ TOCs, respectively, for all possible combinations of land/sea and DT/NT. The most marked differences of DT/NT DOFs are for the column surface- $3 \mathrm{~km}$, with nearly $20 \%$ higher values, on average, of daytime DOFs, reaching mean values as high as 0.61 for the mean daytime surface- $3 \mathrm{~km}$ TOC. The DOFs for surface- $6 \mathrm{~km}$ are less sensitive to DT/NT differences, with mean values of $1.19(+6 \%)$ and 1.12 for the DT and NT subsets. This can be linked to the more important enhancement of the sensitivity at the lowest altitudes, due to the higher thermal contrasts during daytime. The altitude of the maximum sensitivity is at altitudes about $400 \mathrm{~m}$ lower at DT, for both the surface- $6 \mathrm{~km}$ and the surface- $3 \mathrm{~km}$ TOCs. The land/sea differences exhibit a similar behaviour, with a more marked difference for 
the DOF for surface- $3 \mathrm{~km}(+11 \%$ for the DT with respect to the NT subset, for the DOF for surface- $3 \mathrm{~km}$, and $+4 \%$ for the DT with respect to the NT subset, for the DOF for surface- $6 \mathrm{~km}$ ) and a similar small difference, about $200 \mathrm{~m}$, for the altitudes of the maximum sensitivity. It can be noticed that the sensitivity during night time over land surface pixels is similar to the sensitivity during daytime and night time over sea surface pixels, for both the surface- $6 \mathrm{~km}$ and surface $-3 \mathrm{~km}$ TOCs. In those cases, we have found similar mean DOFs (1.11-1.14 and 0.49-0.57, for the DOFs for surface- $6 \mathrm{~km}$ and the DOFs for surface- $-3 \mathrm{~km}$, respectively) and sensitivity only a bit lower (250-300 m and 100-200 m difference, on average, for the surface- $6 \mathrm{~km}$ and surface$3 \mathrm{~km}$ TOC, respectively) for the DT/sea with respect to NT/land and NT/sea. On the contrary, the most important difference of sensitivity is between DT and NT surface$3 \mathrm{~km}$ TOC pseudo-observations taken over land surface pixels. The average DT/land DOF for surface $-3 \mathrm{~km}$ reaches values as high as 0.71 , which is about $24 \%$ higher than DT/sea, more than $30 \%$ higher than NT/land and about $45 \%$ higher than NT/sea. The sensitivity of the DT/land surface $-3 \mathrm{~km}$ TOC pseudo-observations peaks at about $2.1 \mathrm{~km}$, which is about 500, 600 and $700 \mathrm{~m}$ lower than DT/sea, NT/land and NT/sea. The differences of sensitivity for the surface $-6 \mathrm{~km}$ TOC pseudo-observations are less marked, with the average DT/land DOF surface- $6 \mathrm{~km}$ reaching values of 1.27 , which is about $11 \%$ higher than DT/sea, $11 \%$ higher than NT/land and about $14 \%$ higher than NT/sea, and the sensitivity peaking at about $2.7 \mathrm{~km}$, which is about 200,400 and $500 \mathrm{~m}$ lower than DT/sea, NT/land and NT/sea. Following these results we are inclined to consider the DT/NT difference as more important than the land/sea surface difference in the determination of the vertical sensitivity of our MAGEAQTIR pseudo-observations. This impact is markedly more evident on smaller and lower columns, such as the surface $-3 \mathrm{~km}$ TOC.

To further investigate the vertical sensitivity, especially in terms of the surface- $3 \mathrm{~km}$ TOC, Fig. 3 shows the integrated AKs for the surface $-3 \mathrm{~km}, 4-6 \mathrm{~km}$ and surface $-6 \mathrm{~km}$ TOCs, averaged over all pixels of our data set having thermal contrast between 0.0 and $1.0 \mathrm{~K}$. The integrated AKs for the surface $-3 \mathrm{~km}$ and the $4-6 \mathrm{~km}$ TOCs are partially overlapped, thus indicating that, on average, the MAGEAQ-TIR would not be able to completely separate the surface $-3 \mathrm{~km}$ column information. In any case the AKs are not completely overlapped, and therefore it is possible to retrieve partially independent information. This result is coherent with the average DOF of 0.57, as shown in Fig. 2. The AKs for a strongly positive thermal contrast $(>5 \mathrm{~K}$ ) are only a little more separated (not shown here).

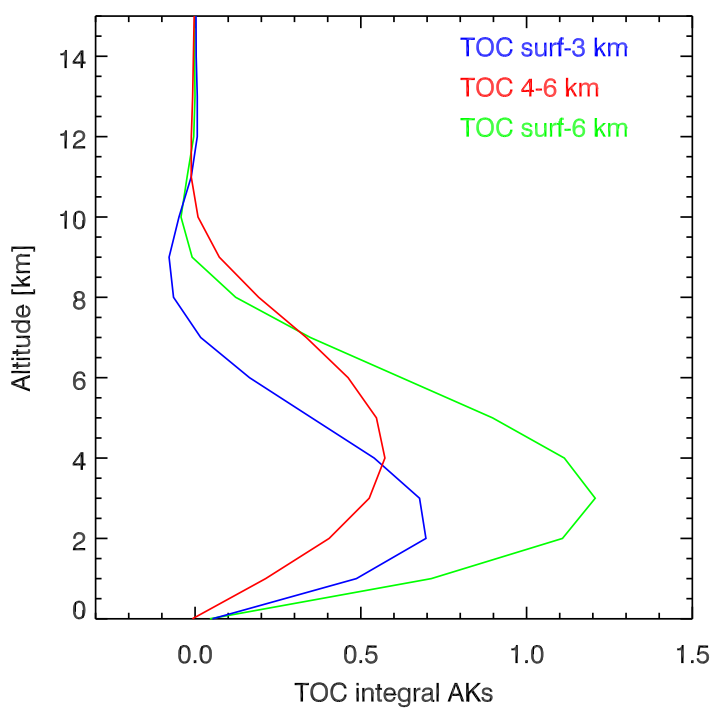

Fig. 3. Mean integral averaging kernel functions for the surface$3 \mathrm{~km}$ (blue), 4-6 km (red) and surface-6 km (green) TOCs, for all pixels in the data set having a thermal contrast between 0 and $1.0 \mathrm{~K}$.

\section{General statistical analysis of the retrieval accuracy}

In the present section, we characterise the accuracy of the MAGEAQ-TIR retrievals, with respect to the MOCAGE pseudo-reality. For all comparisons in this work, we compare the MAGEAQ retrievals with the raw (not smoothed with the retrieval AKs) MOCAGE pseudo-reality. Following Rodgers (1990), our pseudo-observations can be expressed as

$\boldsymbol{x}_{\mathrm{PO}}=\mathbf{A} \boldsymbol{x}_{\mathrm{PR}}+(\mathbb{I}-\mathbf{A}) \boldsymbol{x}_{\mathrm{a}}+\mathbf{G} \boldsymbol{e}$,

where $\boldsymbol{x}_{\mathrm{PO}}, \boldsymbol{x}_{\mathrm{PR}}$ and $\boldsymbol{x}_{\mathrm{a}}$ are the pseudo-observation, pseudoreality and a priori ozone profiles, $\mathbb{I}$ is the unity matrix, $\mathbf{A}$ is the AK matrix, $\mathbf{G}$ is the gain matrix, and $\boldsymbol{e}$ is the radiometric noise. Comparing $\boldsymbol{x}_{\mathrm{PO}}$ and $\boldsymbol{x}_{\mathrm{PR}}$ means evaluating the differences arising from the $\mathbf{A K}$ matrix not being unity, the a priori information not being the truth and for the existence of radiometric noise. Our goal is to evaluate all these components together, thus, the uncertainties coming from both the limited vertical sensitivity and the propagation of the radiometric (measurement noise) error.

Tables 4 and 5 report the mean absolute and percent biases and RMSEs (root mean square errors) of the surface$6 \mathrm{~km}$, and the surface- $3 \mathrm{~km}$ TOC pseudo-observations, respectively. For both columns, the statistical parameters of the comparison are calculated for the whole ensemble of the data, and, as done previously for the vertical sensitivity, for DT/NT and land/sea surface subsets, with all different possible combinations. The MAGEAQ-TIR surface- $6 \mathrm{~km}$ TOC pseudo-observations show biases generally smaller than $1 \%$ in magnitude. Also for the MAGEAQ-TIR surface- $3 \mathrm{~km}$ TOC pseudo-observations the mean biases are small, with an average underestimation of $-2 \%$ over the whole data set. 
Table 2. Mean DOFs for surface-6 km and surface- $3 \mathrm{~km}$ for land/day, land/night, sea/day and sea/night pixels, calculated over the whole data set, on a $1 \mathrm{~h}$ revisit time basis.

\begin{tabular}{lrrrrr}
\hline & \multicolumn{2}{c}{ Day } & & \multicolumn{2}{c}{ Night } \\
\cline { 2 - 3 } \cline { 5 - 6 } Land & DOF surf-6 km & DOF surf-3 km & & DOF surf-6 km & DOF surf-3 km \\
Sea & 1.27 & 0.71 & & 1.14 & 0.54 \\
& 1.14 & 0.57 & & 1.11 & 0.49 \\
\hline
\end{tabular}

Table 3. Mean altitudes of the maximum of the integrated AK for the surface- $6 \mathrm{~km}$ TOC and surface- $3 \mathrm{~km}$ TOC for land/day, land/night, sea/day and sea/night pixels, calculated over the whole data set, on a $1 \mathrm{~h}$ revisit time basis (Max sens: maximum sensitivity).

\begin{tabular}{|c|c|c|c|c|}
\hline \multirow{4}{*}{ Land } & \multicolumn{2}{|c|}{ Daytime } & \multicolumn{2}{|c|}{ Night time } \\
\hline & Max sens surf- $6 \mathrm{~km}$ & Max sens surf- $3 \mathrm{~km}$ & Max sens surf-6 km & Max sens surf $-3 \mathrm{~km}$ \\
\hline & $2.67 \mathrm{~km}$ & $2.09 \mathrm{~km}$ & $3.10 \mathrm{~km}$ & $2.70 \mathrm{~km}$ \\
\hline & $2.85 \mathrm{~km}$ & $2.60 \mathrm{~km}$ & $3.15 \mathrm{~km}$ & $2.82 \mathrm{~km}$ \\
\hline
\end{tabular}

The mean bias of the surface- $3 \mathrm{~km}$ TOC is mostly driven by the surface type, with values between -1.4 and $-1.9 \%$ over land, and between -2.7 and $-3.1 \%$ over sea. The RMSEs have a value of $1.28 \mathrm{DU}(5.3 \%)$, for the column surface$6 \mathrm{~km}$, and $1.53 \mathrm{DU}(10.4 \%)$, for the column surface- $3 \mathrm{~km}$. The RMSEs for both columns are mostly driven by the time at which observations are done. We observe no big DT/NT differences over sea, with a slightly better performance of the NT subset. On the contrary, we observe very large DT/NT differences over land, with DT RMSEs smaller than 45 and $30 \%$, for the surface- $6 \mathrm{~km}$ and surface $-3 \mathrm{~km}$ TOCs. The smallest values of the RMSEs are found for the DT/land subset. The average DT/land RMSE for the surface- $6 \mathrm{~km}$ TOC reaches values as low as $0.92 \mathrm{DU}(3.8 \%)$, which is about $35 \%$ smaller than DT/sea, about $45 \%$ smaller than NT/land and about $32 \%$ smaller than NT/sea. The average DT/land RMSE for the surface- $3 \mathrm{~km}$ TOC reaches values as low as $1.25 \mathrm{DU}(8.8 \%)$, which is about $20 \%$ smaller than DT/sea, about $30 \%$ smaller than NT/land and about $15 \%$ smaller than NT/sea.

To characterise the global data set in terms of the spatial distribution, Figs. 4 and 5 show the average surface- $6 \mathrm{~km}$ and surface- $3 \mathrm{~km}$ TOCs, for the whole data set, over Europe. The figures display the MOCAGE pseudo-reality, MOCAGE smoothed with the MAGEAQ-TIR AK, the MAGEAQ pseudo-observations and the difference between MAGEAQTIR pseudo-observations and MOCAGE pseudo-reality, for the whole data set and for DT-only and NT-only subsets. The average distributions of lower and lowermost tropospheric ozone are in general well caught by the MAGEAQTIR pseudo-observations. The MAGEAQ-MOCAGE differences are typically in the interval $\pm 0.5 \mathrm{DU}( \pm 2 \%)$ for the surface $-6 \mathrm{~km}$ TOC, and $\pm 1.0 \mathrm{DU}( \pm 6 \%)$ for the surface$3 \mathrm{~km}$ TOC. For both surface- $6 \mathrm{~km}$ and surface $-3 \mathrm{~km}$, and at both DT and NT, a relatively marked underestimation in the Mediterranean Basin is found. Typical underestimations in that area are of the order of 2.0-2.5 DU ( 7-8\%) for the surface-6 km TOC, and 3.0-3.5 DU ( 15-18\%) for the surface $-3 \mathrm{~km}$ TOC. This underestimation area touches also a southern European continental portion during NT.

\section{Time series of the lower tropospheric ozone columns}

In the present section, we study the capability of the MAGEAQ-TIR pseudo-observations to follow the temporal evolutions of the lower (up to $6 \mathrm{~km}$ ) and lowermost (up to $3 \mathrm{~km}$ ) tropospheric ozone columns. We focus on the local scale and then we select very small regions, of the order of $0.2^{\circ} \times 0.2^{\circ}$. To study both urban and remote environments, we have selected six locations: Milan (Italy), Paris (France), Berlin (Germany), Amsterdam (the Netherlands), one marine location west of Norway's coast $\left(55^{\circ} \mathrm{N}, 8^{\circ} \mathrm{E}\right)$, and Barcelona (Spain). Paris, Berlin and Amsterdam, and Milan and Barcelona, have been chosen to study the performance of MAGEAQ-TIR at northern and at southern European urban locations. The marine location west of Norway has been selected for the study of one particular remote, marine location, affected by the transport of ozone-polluted air masses in the period of study. In fact, Forêt et al. (2013) and Sellitto et al. $(2013, \mathrm{~b})$ have shown that a peculiar ozone plume phenomena affected this area during August 2009. The strong values of ozone observed in the boundary layer over the south of France, due to photochemical production, are transported to higher altitudes (up to $1-2 \mathrm{~km}$ altitude) and then transported eastwards and northwards. The plume then reached the mentioned marine location on 20 August after having passed over Paris and, almost at the same time, Amsterdam. Afterwards, the plume was observed over Berlin. Therefore, choosing these locations gives us the possibility to further analyse the capability of MAGEAQ-TIR pseudo-observations to observe this transport phenomenon. Figures 6 and 7 display the time series of MOCAGE raw pseudo-reality and MAGEAQ-TIR pseudo-observations of the surface- $6 \mathrm{~km}$ and surface- $3 \mathrm{~km}$ 

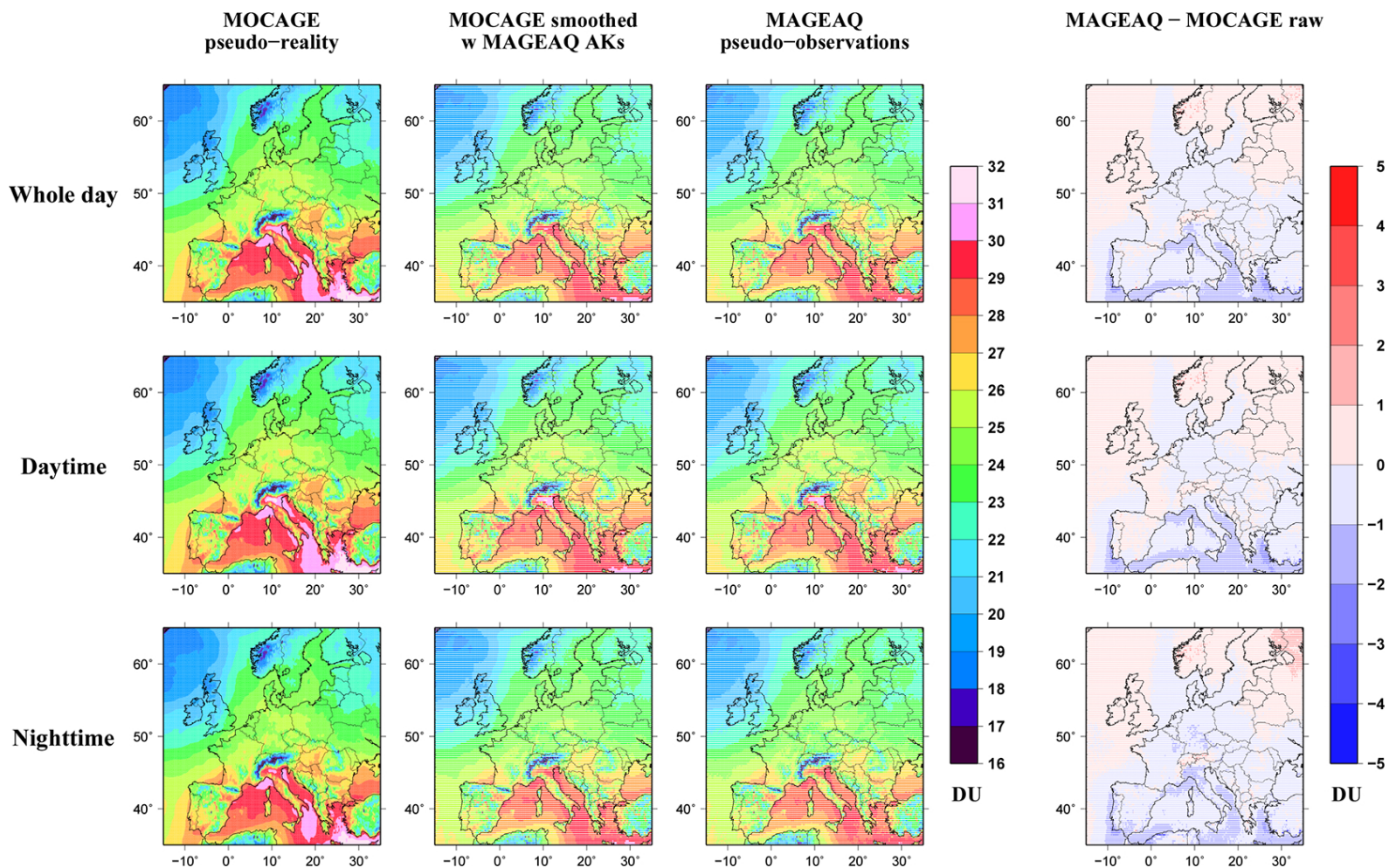

Fig. 4. Average surface-6 km TOC for 5-28 August 2009. From left to right: raw and AK-smoothed MOCAGE pseudo-reality, MAGEAQTIR pseudo-observations, differences of MAGEAQ-TIR pseudo-observations with respect to raw MOCAGE pseudo-reality. The average TOCs are reported for the whole day (top row), daytime (central row) and night time acquisitions (bottom row).
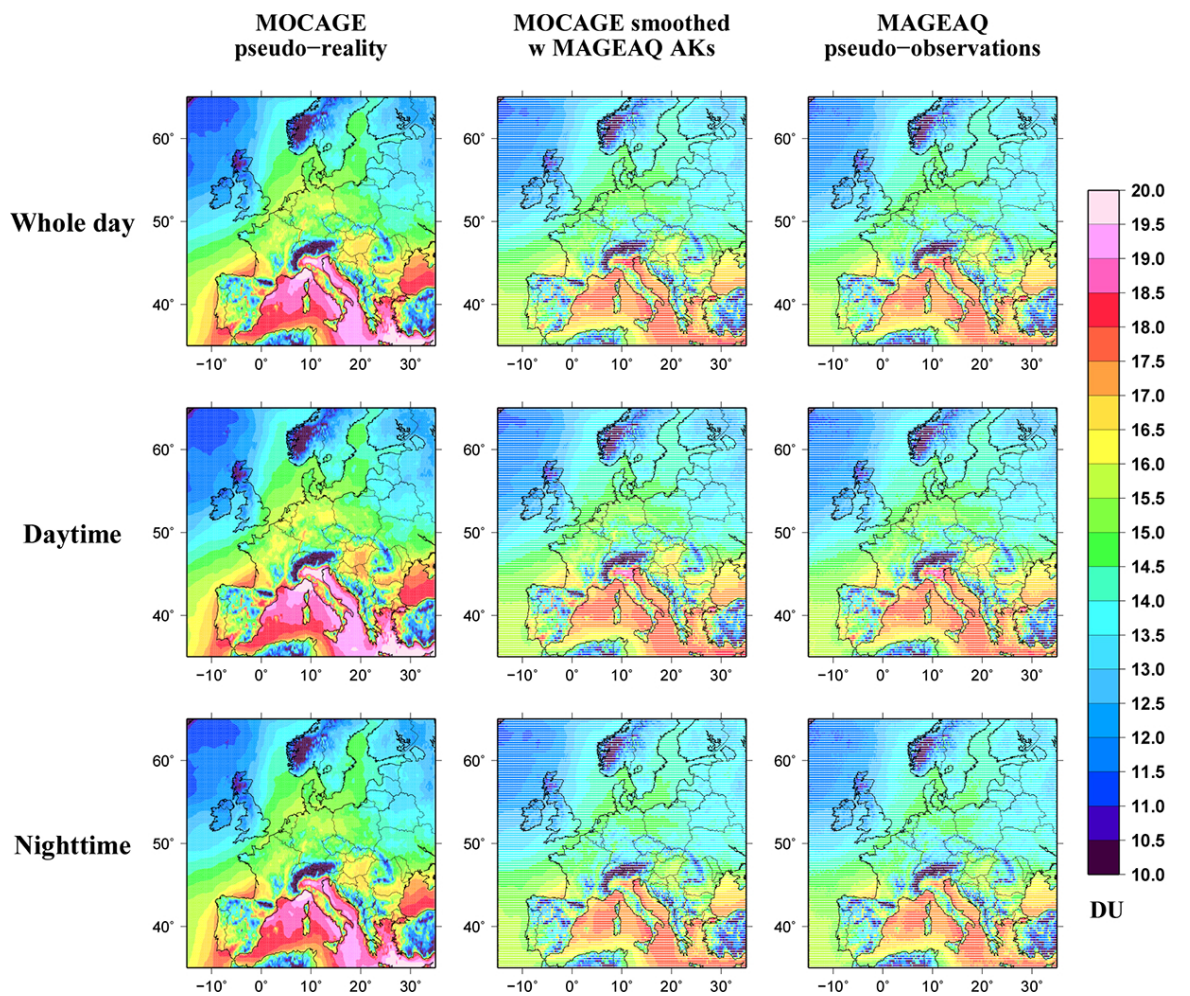

MAGEAQ - MOCAGE raw
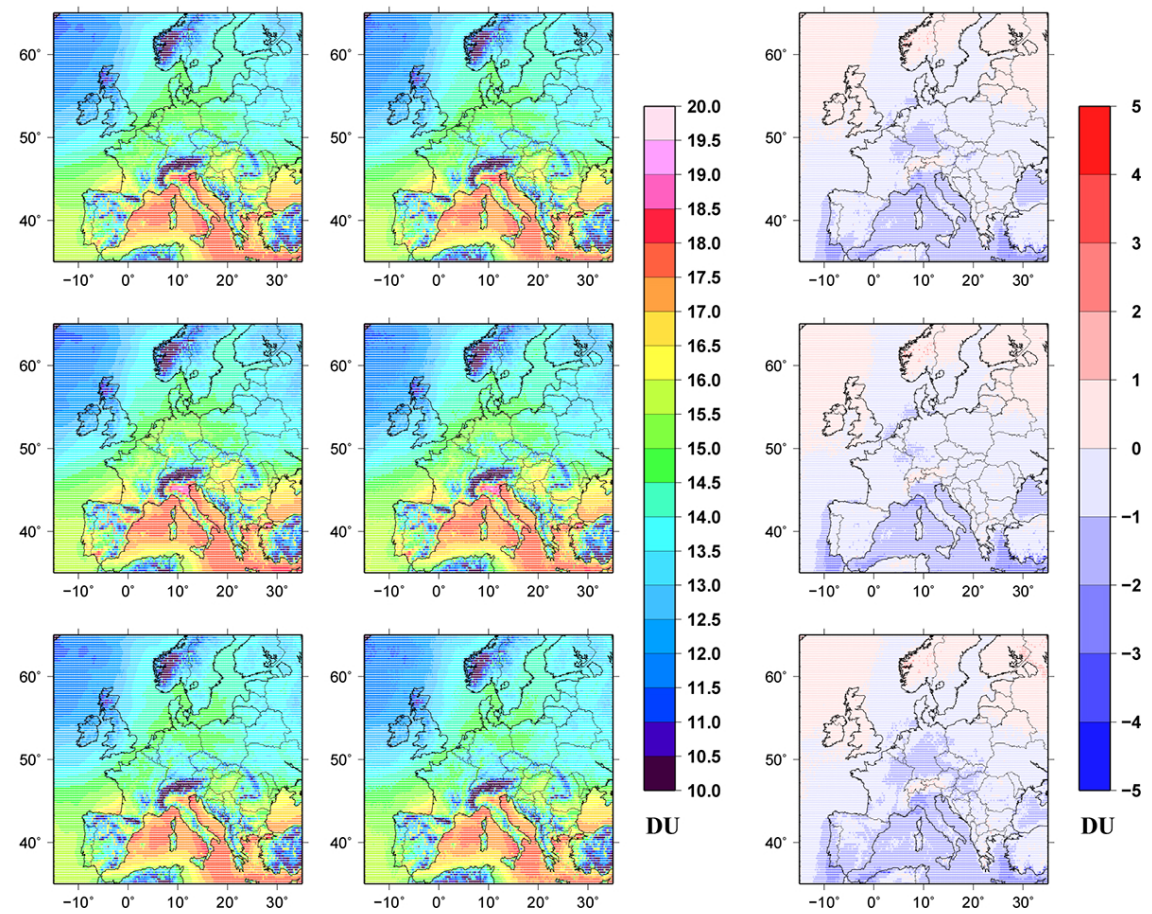

Fig. 5. Same as Fig. 4 but for surface- 3 km TOCs. 
Table 4. Mean biases and RMSEs of MAGEAQ-TIR surface-6 km TOC pseudo-observations, with respect to MOCAGE pseudo-reality. Results are reported for all data, land (sea) only, DT (NT) only, and all various combinations. Percent values of biases and RMSEs are reported in parentheses.

\begin{tabular}{|c|c|c|c|c|c|c|}
\hline \multirow[b]{3}{*}{ Daily } & \multicolumn{2}{|c|}{ Land + sea } & \multicolumn{2}{|c|}{ Land } & \multicolumn{2}{|c|}{ Sea } \\
\hline & Bias [DU (\%)] & RMSE [DU (\%)] & Bias [DU (\%)] & RMSE [DU (\%)] & Bias [DU (\%)] & RMSE [DU $(\%)]$ \\
\hline & $-0.16(-0.30 \%)$ & $1.28(5.28 \%)$ & $-0.01(-0.27 \%)$ & $1.17(4.81 \%)$ & $-0.32(-0.93 \%)$ & $1.38(5.68 \%)$ \\
\hline DT & $-0.12(-0.16 \%)$ & $1.06(4.35 \%)$ & $+0.10(+0.62 \%)$ & $0.92(3.82 \%)$ & $-0.35(-1.02 \%)$ & $1.41(5.73 \%)$ \\
\hline NT & $-0.20(-0.43 \%)$ & $1.47(6.05 \%)$ & $-0.11(-0.62 \%)$ & $1.61(6.13 \%)$ & $-0.30(-0.84 \%)$ & $1.36(5.52 \%)$ \\
\hline
\end{tabular}

Table 5. Same as Table 4 but for surface- $3 \mathrm{~km}$ TOC pseudo-observations.

\begin{tabular}{|c|c|c|c|c|c|c|}
\hline \multirow[b]{3}{*}{ Daily } & \multicolumn{2}{|c|}{ Land + sea } & \multicolumn{2}{|c|}{ Land } & \multicolumn{2}{|c|}{ Sea } \\
\hline & Bias [DU (\%)] & RMSE [DU (\%)] & Bias [DU (\%)] & RMSE [DU (\%)] & Bias [DU (\%)] & RMSE [DU (\%)] \\
\hline & $-0.47(-2.24 \%)$ & $1.53(10.39 \%)$ & $-0.36(-1.65 \%)$ & $1.51(10.29 \%)$ & $-0.60(-2.88 \%)$ & $1.55(10.53 \%)$ \\
\hline DT & $-0.46(-2.19 \%)$ & $1.42(9.62 \%)$ & $-0.30(-1.40 \%)$ & $1.25(8.78 \%)$ & $-0.63(-3.06 \%)$ & $1.59(10.35 \%)$ \\
\hline NT & $-0.49(-2.28 \%)$ & $1.62(11.14 \%)$ & $-0.42(-1.90 \%)$ & $1.73(12.26 \%)$ & $-0.56(-2.71 \%)$ & $1.51(9.95 \%)$ \\
\hline
\end{tabular}

TOCs, respectively, over these locations. As a complement to these figures, in Fig. 8 we show the time series for the DOF surface- $6 \mathrm{~km}$ and surface $-3 \mathrm{~km}$ at the same locations. The general features of the pseudo-observations time series are stunningly coherent with the pseudo-reality, in particular for the surface- $6 \mathrm{~km}$ TOC, except for Milan, and, to a lesser extent, Barcelona. This evidences how the retrieval is more problematic over southern European urban locations. More details on this aspect will be given in Sect. 6, where we show how our pseudo-observations fail to describe the daily cycle at Milan on a height-resolved basis, due to a smaller sensitivity to the lowest layers, where this cycle is more pronounced. This behaviour has a marked effect also on the surface- $3 \mathrm{~km}$ and, to a lesser extent on the surface- $6 \mathrm{~km}$ TOCs. For Milan (first panel in Fig. 8), the DOF for surface-6 km and surface$3 \mathrm{~km}$ has a marked daily cycle, with a maximum $/$ minimum at about 12:00/24:00 UTC. The differences between the maxima and minima can be of the order of the $40 \%$ (minimum 1.0 DOF, maximum 1.4 DOF) for the surface- $6 \mathrm{~km}$ column, and can reach $100 \%$ (minimum $0.4 \mathrm{DOF}$, maximum $0.8 \mathrm{DOF}$ ) for the surface- $3 \mathrm{~km}$ column. While the maximum of sensitivity is at about 12:00 UTC, the maximum of the pseudo-reality ozone concentrations at the lowest altitudes is at about 15:00 UTC. Consequently, the highest values at the lowest altitudes after 12:00 UTC are generally underestimated. This generates quite a strong artifact cycle at Milan, with a maximum which is shifted back some hours. This effect is also present in the surface- $3 \mathrm{~km}$ TOC time series of Barcelona, e.g. for the days 10, 11, 26 and 27 August. The other urban locations have pseudo-reality time series less driven by the daily cycle, and thus are less sensitive to this effect, which is only sporadically observed on the surface$3 \mathrm{~km}$ TOC time series. We quantify the performance of our MAGEAQ-TIR synthetic observations by the mean biases, RMSEs and the Pearson correlation coefficients, with respect to the pseudo-reality, at the six locations. These quantities are summarised in Table 6 , for the surface- $6 \mathrm{~km}$ TOCs, and in Table 7, for the surface- $3 \mathrm{~km}$ TOCs. For the surface- $6 \mathrm{~km}$ TOC pseudo-observations, the values of the correlation coefficients are in the range 0.93-0.97 for Paris, Berlin, Amsterdam and the North Sea, while it decreases to 0.89 and 0.82 for Barcelona and Milan. The biases are very small $(<0.35 \%$ in magnitude) at the northern European urban locations, while a more significant systematic underestimation is observed over the North Sea, -0.46 DU $(-1.54 \%)$, and higher values at the southern European urban locations, reaching the value of $-1.29 \mathrm{DU}(-4.25 \%)$ at Milan. The near zero bias at the northern urban locations, and the small underestimation over the North Sea, are consistent with the average land/sea biases shown in Table 4 . The negative biases at the two southern European urban locations, in particular at Milan, are a marked anomaly in our data set. Also, the RMSEs show this behaviour, with values in the range 1.081.19 DU (4.09-4.62\%), except for Milan, which has a mean value of $1.96 \mathrm{DU}(6.43 \%)$. As for the surface $-3 \mathrm{~km}$ TOC, the Pearson coefficients have values of 0.83-0.91 over northern European urban locations, 0.73 at Barcelona and 0.55 at $\mathrm{Mi}-$ lan. There are stronger systematic underestimations than for the general characterisation of the data set, of the order of -3 to $-5 \%$, and even higher values for Barcelona $(-6.5 \%)$ and Milan $(-10.82 \%)$. The RMSEs are of a similar magnitude as for the general characterisation (1.4-1.7 DU, i.e. 9$10 \%$ ), except for Milan which exhibits higher values, reaching $2.7 \mathrm{DU}(13.5 \%)$.

To summarise, we have found that our MAGEAQ-TIR pseudo-observations are capable of following the pseudoreality lower and lowermost tropospheric ozone column's temporal evolutions at a local scale (at selected locations), even if artifacts in the column's time series, especially for the surface- $3 \mathrm{~km}$ TOC, at southern European urban locations are observed. 

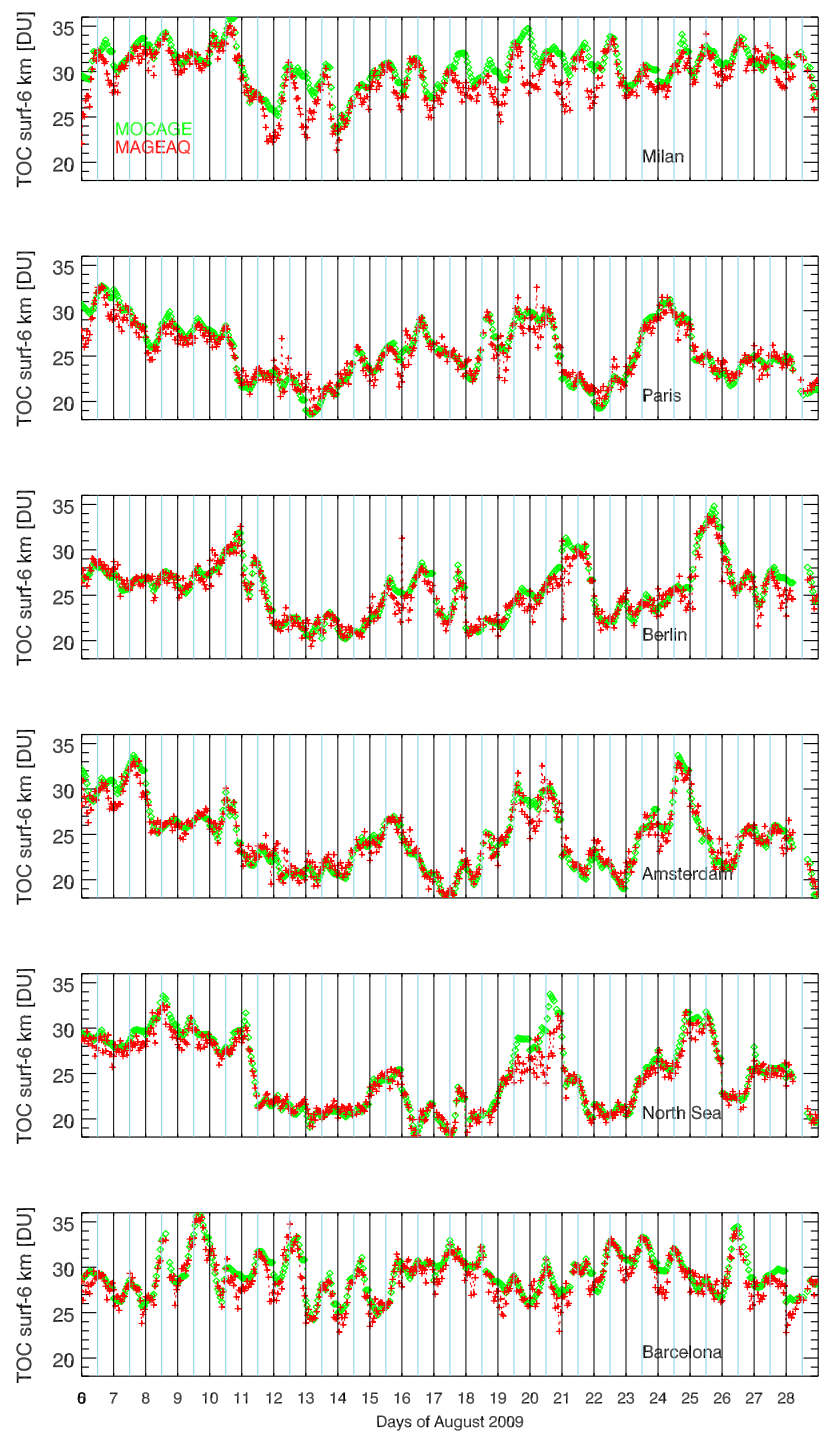

Fig. 6. Time series of MOCAGE surface- $6 \mathrm{~km}$ TOC pseudoreality (green), and MAGEAQ-TIR surface-6 km TOC pseudoobservations (red) over Milan, Paris, Berlin, Amsterdam, the marine location west of Norway's coast, and Barcelona.

\section{Vertical distribution}

Here, we evaluate if the synthetic MAGEAQ-TIR observations can detect different phenomena occurring at and influencing different altitude ranges. In particular, we try to understand to which extent MAGEAQ-TIR may be able to detect enhanced ozone values near the surface and then the photochemistry ozone production signal. Studying only the surface- $6 \mathrm{~km}$ or even the surface $-3 \mathrm{~km}$ ozone columns is not sufficient to answer this question, because these columns can be only partially influenced by the phenomena occurring in the boundary layer and this effect may be difficult to sort out from other concurring phenomena, such as STEs or transport into the free troposphere. As for Sect. 5, we focus our
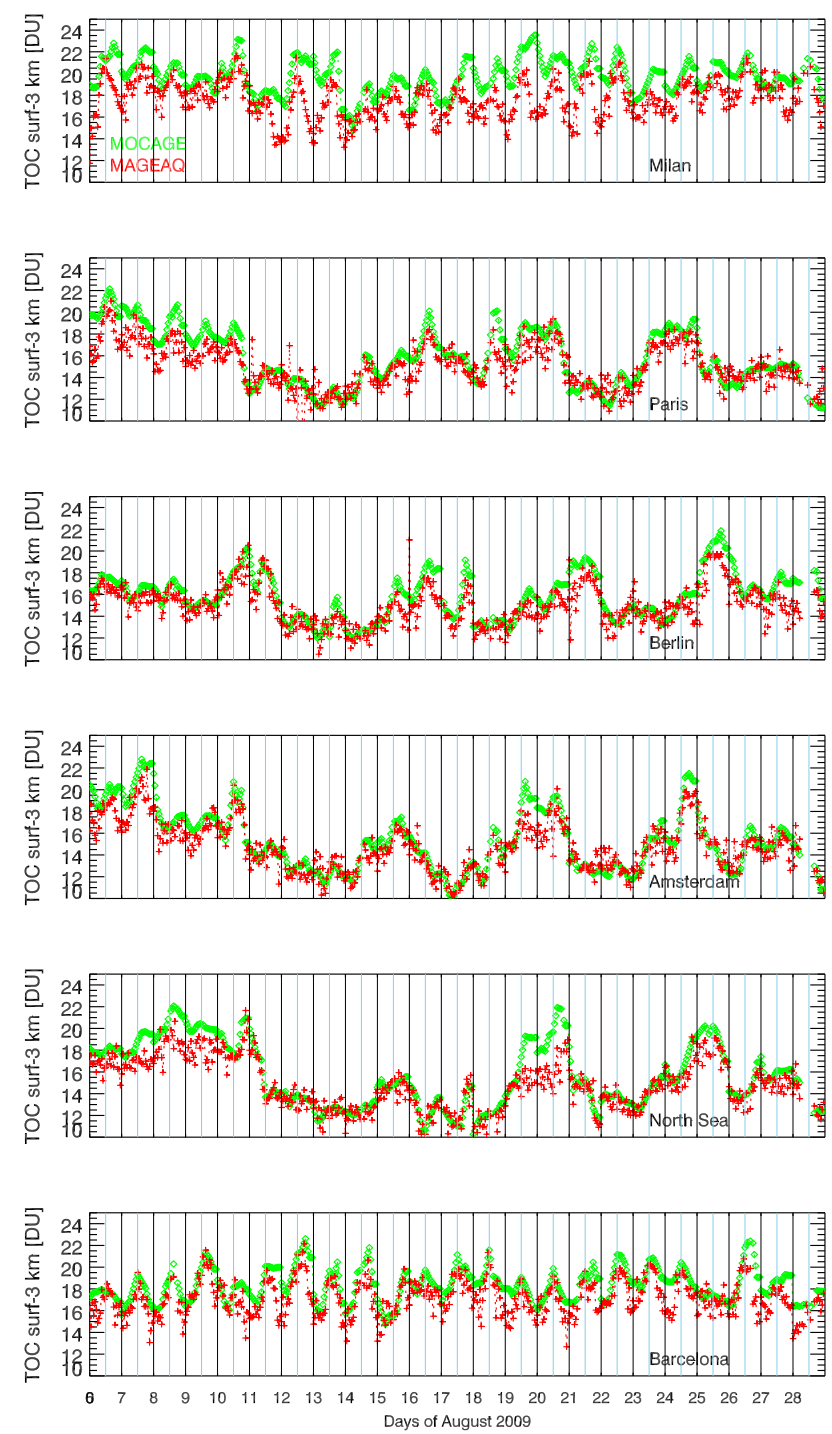

Fig. 7. Same as Fig. 6 but for surface $-3 \mathrm{~km}$ TOCs.

analysis on the same small regions: Milan, Paris, Berlin, Amsterdam, the marine location west of Norway's coast, and Barcelona.

Figure 9 shows the mean ozone concentration profile of pseudo-observations and pseudo-reality, with standard deviations. The MAGEAQ-TIR synthetic observations have very consistent variability (in terms of the standard deviations) and mean value, with respect to MOCAGE pseudo-reality, in the interval $2-7 \mathrm{~km}$. On the contrary, the MAGEAQ-TIR synthetic observations cannot replicate the variability of the pseudo-reality at the two lowest levels, especially at the surface. There, the pseudo-reality standard deviations are in the interval 9-23 ppb (parts per billion), while the pseudoobservation standard deviations are in the interval 3-5 ppb. The underestimation of the surface variability ranges from $55 \%$ at the marine location over the North Sea (MOCAGE 

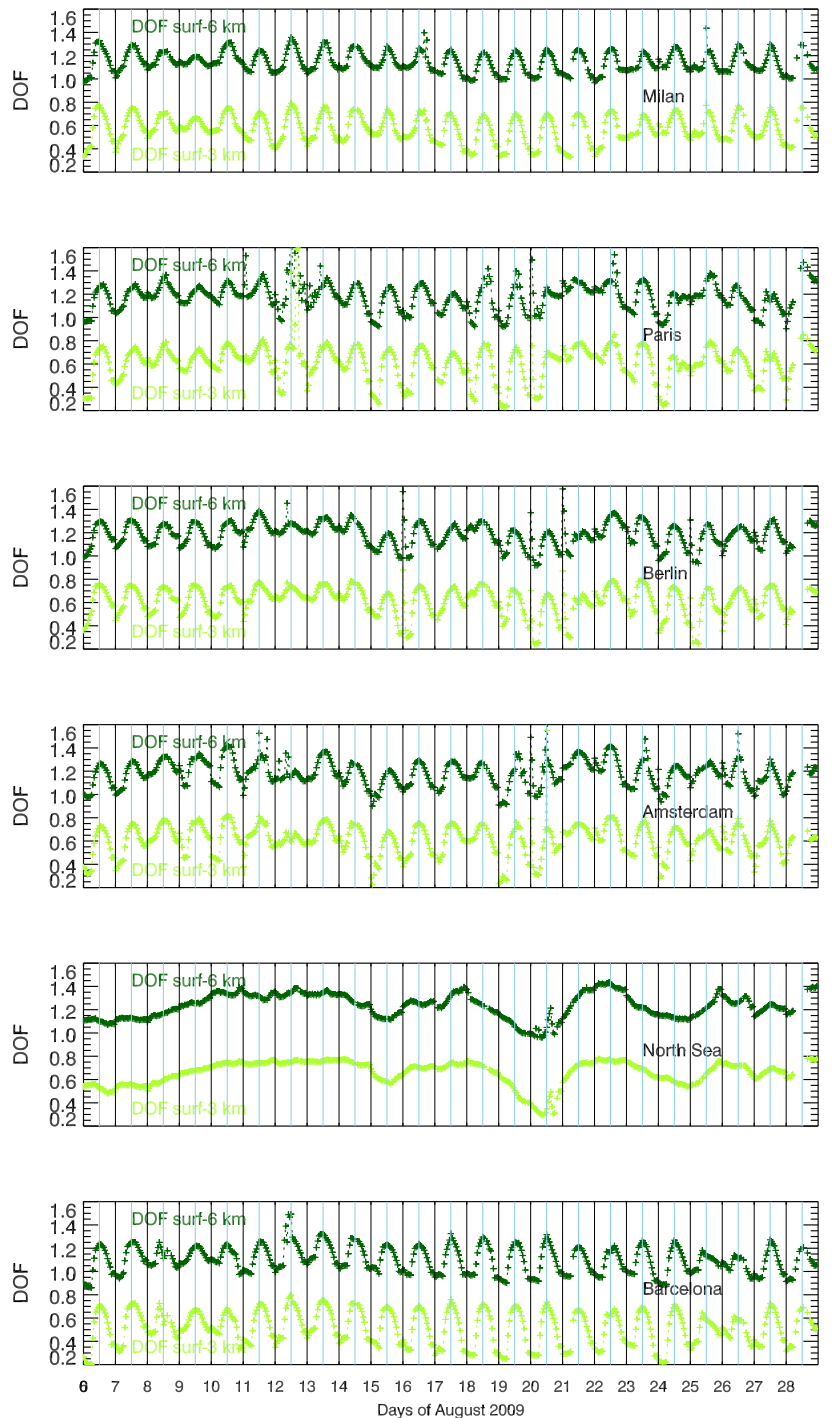

Fig. 8. Time series of the DOFs for surface- $6 \mathrm{~km}$ (dark green) and surface- 3 km (light green) over Milan, Paris, Berlin, Amsterdam, the marine location west of Norway's coast, and Barcelona.

standard deviation $9 \mathrm{ppb}$, MAGEAQ-TIR standard deviation $4 \mathrm{ppb}$ ) to $87 \%$ at Barcelona (MOCAGE standard deviation $23 \mathrm{ppb}$, MAGEAQ-TIR standard deviation $3 \mathrm{ppb}$ ). The urban locations have larger pseudo-reality variability and larger underestimations of the pseudo-observation variability, in particular at the southern Europe subsection (87 and $85 \%$ smaller standard deviations at Barcelona and Milan; 64, 70 and $67 \%$ smaller standard deviations at Paris, Berlin and Amsterdam). The small variability of the MAGEAQ-TIR synthetic observations at the surface are easily attributable to the scarce sensitivity at that altitude. Therefore, the spectral information has not the potential to modulate the concentrations from the a priori. Also, the average pseudoobservation profiles show an underestimation with respect to the pseudo-reality at the lowest layer, which can extend up to
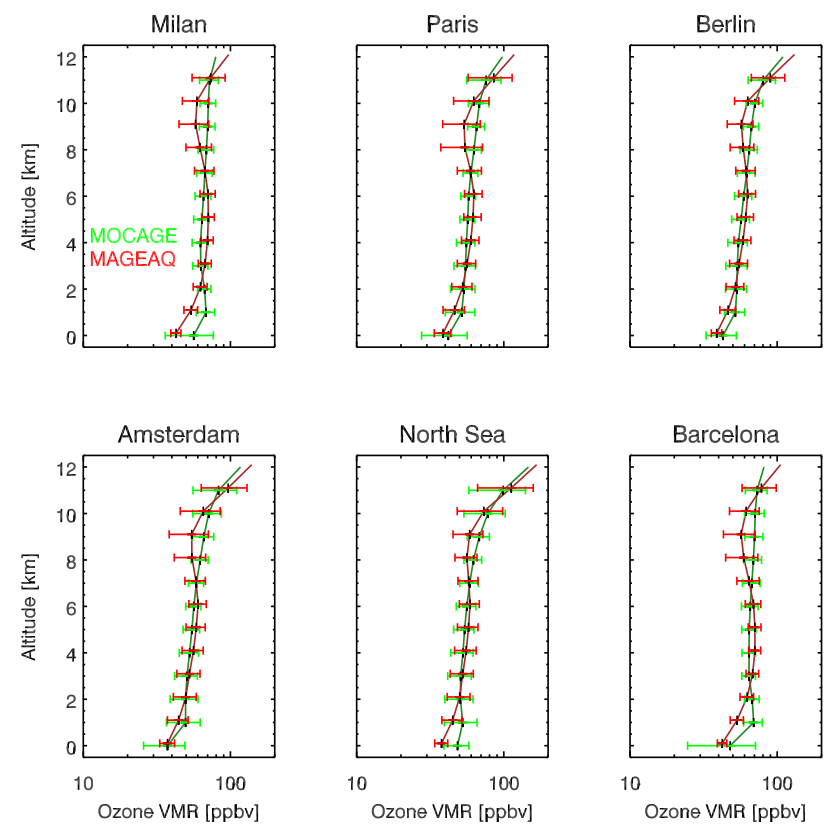

Fig. 9. Mean tropospheric ozone concentration profiles: MOCAGE pseudo-reality (green) and MAGEAQ-TIR pseudo-observation (red), at Milan (Italy), Paris (France), Berlin (Germany), Amsterdam (the Netherlands), one marine location west of Norway's coast $\left(55^{\circ} \mathrm{N}, 8^{\circ} \mathrm{E}\right)$, and Barcelona (Spain). Error bars indicate the standard deviations.

$1 \mathrm{~km}$ altitude at some locations. This effect is more marked, for example, at Milan. Another systematic behaviour of the MAGEAQ-TIR pseudo-observations is the marked underestimation of several retrievals in the height interval $7-11 \mathrm{~km}$, at all locations. This may come from a compensation effect due to the limited vertical resolution of the retrieval. At the operational level, filtering out these unrealistic retrievals, or using stronger Tikhonov-Phillips constraints or a more complex a priori definition, may be a possible solution to limit the impact of these artifacts.

To study the time series of the profiles, in Fig. 10 we show the Hovmöller diagrams of tropospheric ozone profile from MOCAGE pseudo-reality and MAGEAQ-TIR pseudoobservations, at four locations: Milan, Paris, Amsterdam and the marine location west of Norway's coast. The considered altitude interval is surface- $12 \mathrm{~km}$, with a $1 \mathrm{~km}$ vertical sampling, which reflects the output grid of our simulator. For each of the four locations, a further plot is shown, with the height-resolved percent differences of MAGEAQTIR pseudo-observations versus MOCAGE pseudo-reality. Some general features appear. Over all locations, two main altitude intervals emerge with more marked differences of the pseudo-observations with respect to the pseudo-reality: between 7 and $11 \mathrm{~km}$ and from surface to $2 \mathrm{~km}$. Both effects are systematic underestimations. The underestimations are linked to the general behaviour discussed in the 
Table 6. Mean biases, RMSEs and Pearson correlation coefficients of MAGEAQ-TIR surface-6 km TOC pseudo-observations, with respect to MOCAGE pseudo-reality, at six selected locations. Results are reported for Milan, Paris, Berlin, Amsterdam, the marine location west of Norway's coast, and Barcelona. Percent values of biases and RMSEs are reported in parentheses.

\begin{tabular}{lrrrrrr}
\hline & Milan & Paris & Berlin & Amsterdam & North Sea & Barcelona \\
\hline Bias & $-1.29(-4.25 \%)$ & $-0.15(-0.34 \%)$ & $-0.29(-0.99 \%)$ & $-0.06(-0.00 \%)$ & $-0.46(-1.54 \%)$ & $-0.57(-1.93 \%)$ \\
RMSE & $1.96(6.43 \%)$ & $1.08(4.23 \%)$ & $1.08(4.22 \%)$ & $1.03(4.20 \%)$ & $1.15(4.62 \%)$ & $1.19(4.09 \%)$ \\
Pearson & 0.82 & 0.95 & 0.93 & 0.96 & 0.97 & 0.89 \\
\hline
\end{tabular}

Table 7. Same as Fig. 6 but for the surface- $3 \mathrm{~km}$ TOCs.

\begin{tabular}{lrrrrrr}
\hline & Milan & Paris & Berlin & Amsterdam & North Sea & Barcelona \\
\hline Bias & $-2.17(-10.82 \%)$ & $-0.82(-4.39 \%)$ & $-0.85(-4.99 \%)$ & $-0.60(-3.11 \%)$ & $-0.89(-4.91 \%)$ & $-1.22(-6.56 \%)$ \\
RMSE & $2.67(13.54 \%)$ & $1.54(9.70 \%)$ & $1.41(8.92 \%)$ & $1.37(8.93 \%)$ & $1.54(9.77 \%)$ & $1.67(9.10 \%)$ \\
Pearson & 0.55 & 0.87 & 0.83 & 0.91 & 0.91 & 0.73 \\
\hline
\end{tabular}
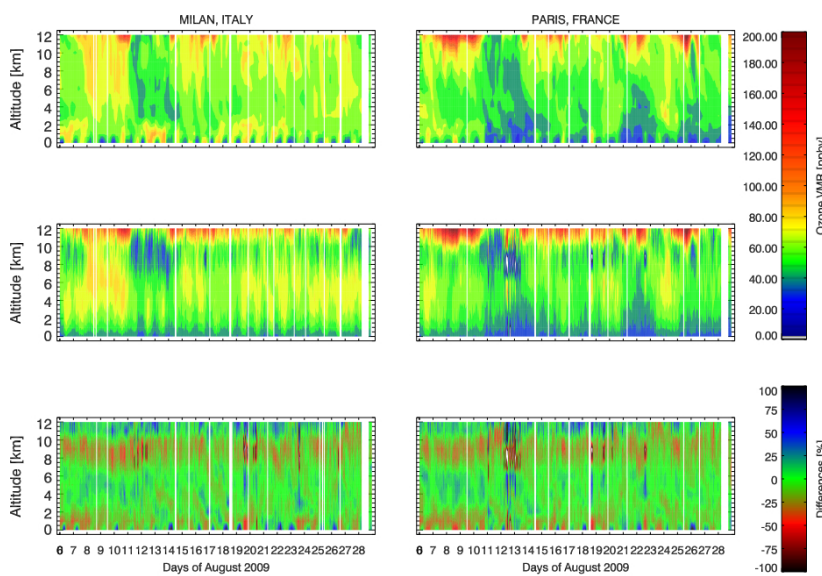

AMSTERDAM, THE NETHERLANDS
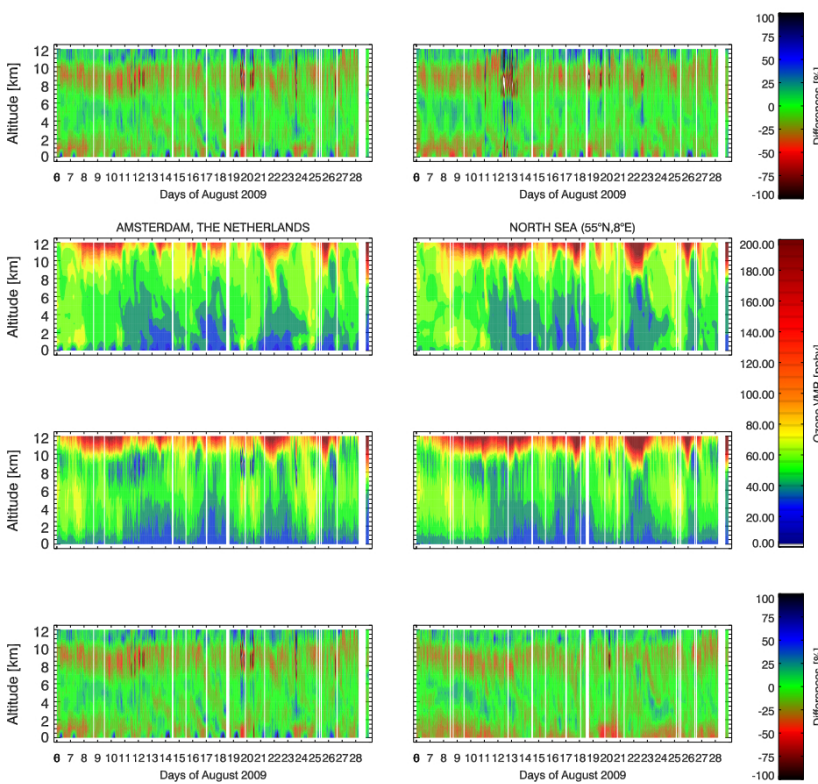

Fig. 10. Hovmöller diagrams showing the MOCAGE pseudo-reality (lines 1 and 4), MAGEAQ-TIR pseudo-observations (lines 2 and 5) and the percent differences (lines 3 and 6) for the tropospheric ozone concentration profiles over Milan, Paris, Amsterdam, the marine location west of Norway's coast, for the whole time period of our study. previous paragraph, with reference to Fig. 9. The compensation/numerical instability effect generate the marked underestimation (up to $50 \%$ ) in the altitude interval 7-11 km. Consequently, the Hovmöller diagrams of MAGEAQ-TIR pseudo-observations show low-value artifacts in that height interval, e.g. between 11 August and 15 August at Milan, 12 August and 13 August at Paris, 11 August and $13 \mathrm{Au}-$ gust at Amsterdam and over the North Sea, and many other smaller spots. The lack of sensitivity at surface- $1 \mathrm{~km}$ is responsible for the underestimation of the daily cycle variability, apparent in the pseudo-reality's lowest layers. This effect is very important at Milan. Then, to describe this behaviour, we concentrate on Milan but these considerations can be, to some extent, extended to the other urban locations. Higher and smaller values of the ozone concentration alternate at the surface, for the MOCAGE pseudo-reality, depending on the hour. A typical diurnal cycle is characterised by values of $10-30 \mathrm{ppb}$ for the night time minimum and 70-90 ppb for the daytime maximum. The air masses enriched in ozone during the day are then mixed to higher level air masses and, during the night, values of typically $70-90 \mathrm{ppb}$ are found in the height interval $1-3 \mathrm{~km}$. This trend is found during weekdays, but not during the weekends of 8-9, 15-16 and 22-23 August 2009. This is due to the limited emission of ozone photochemical precursors during weekends at urban or industrial locations. These complex, urban, lowermost tropospheric ozone patterns are a natural choice as a test for MAGEAQTIR pseudo-observations. The MAGEAQ-TIR retrievals almost completely miss this daily/weekly evolution at the lowest levels. The signatures of these enhancements at the lowest levels are spread onto higher altitudes, and the information content is redistributed accordingly. This indicates that a potential sensitivity exists that might be exploited by tuning the inversion schemes. In any case, with the present configuration, the day/night cycle at the surface and the lifting of enhanced ozone air masses during the night are not detected. 
An attenuated day/night cycle is detected at $1 \mathrm{~km}$ altitude, but it is independent on the weekday. Such kind of structures are not also detected at Paris and Amsterdam. We are then inclined to conclude that a dedicated observing system like MAGEAQ-TIR may have the potential to partially detect the photochemistry signal at the lowest atmospheric layers, which occurs at timescales of the order of hours.

Another phenomenon which is not accurately detected is the one occurring over the North Sea on 20-21 August. The unusually high values of the ozone concentrations at the surface and $1 \mathrm{~km}$ altitude can be related to the ozone pollution event described by Forêt et al. (2013). During the period 19-21 August 2009, high values of lower tropospheric ozone, which are formed in the boundary layer over the south of France, are lifted to the free troposphere and then transported by a frontal motion, northwards and eastwards. The plume crosses this North Sea location during the days 20 and 21 August. It can be seen that MAGEAQ-TIR is not able to detect the peculiar vertical distribution at the lowest layers associated to this phenomenon. The same plume is observed on 20 August over Amsterdam. Even if also here the vertical distribution of this phenomenon is missed, we can see enhanced values of ozone concentration at the highest altitudes, i.e. between 2 and $7 \mathrm{~km}$, maybe due to smoothing errors of the retrieval. This behaviour, at Amsterdam, gives the possibility to detect the signal of this ozone plume in the ozone columns time series (see Sect. 5), even if the height resolved structures are not detected. Phenomena occurring at different altitude ranges, where the retrievals are more sensitive, and/or at different timescales, are better retrieved. One possible example are the enhanced values of ozone concentrations extending from the upper troposphere, and possible also from the tropopause and the stratosphere, to the lower troposphere. Some examples are in the period 7-11 August at Milan, and 24-25 August at Paris and Amsterdam. These phenomena might be attributed to STEs. The enhanced values of the ozone concentration extend down to $4 \mathrm{~km}$ altitude. The phenomenon of 24-25 August has also the particularity of occurring in a very short time interval (1 day). These structures are very well resolved by the MAGEAQ-TIR, and we found very limited signatures in the Hovmöller diagrams of the differences. Other well resolved structures are the peculiar low values of ozone concentration extending from the surface to 5-8 km in the time intervals 11-14 August and 2123 August at Paris, and 12-15 August, 16-19 August and 21-24 August at Amsterdam and over the North Sea.

\section{Conclusions}

We have shown some performance analyses for a future GEO instrument operating in the TIR spectral range, based on the instrumental specifications of MAGEAQ-TIR, following its phase 0 study (Peuch et al., 2010). The instrumental design of MAGEAQ-TIR is thought to be adapted to the lower and lowermost ozone monitoring. We have extended the study of Claeyman et al. (2011b), to test and specify the performance of MAGEAQ-TIR over a bigger data set, with a variety of different situations, and to test its capability to observe height-resolved phenomena. This has allowed, as well, the identification of the causes of poor performance. In addition, the synthetic data have been analysed at urban and rural locations, and the performance in presence of different phenomena occurring at different timescales, e.g. STEs, photochemistry, horizontal transport, have been tested. The period 5-28 August 2009, on a $1 \mathrm{~h}$ revisit time basis, has been considered.

First, we have characterised the vertical sensitivity and the retrieval accuracy of MAGEAQ-TIR pseudo-observations, in a global manner. By analysing the data set as a whole, we have found that the MAGEAQ-TIR would give, on average, independent surface- $6 \mathrm{~km}$ TOC observations, with mean DOF of about 1.0 and a maximum sensitivity at about $3.0 \mathrm{~km}$, thus, at the centre of the column. There would also be an unprecedented sensitivity to the surface $-3 \mathrm{~km}$ TOC, with about $0.6 \mathrm{DOF}$ and maximum sensitivity at about $2.5 \mathrm{~km}$, on average. Even if MAGEAQ-TIR cannot completely separate the surface $-3 \mathrm{~km}$ TOC information from the information coming from upper altitudes, the DOF surface- $3 \mathrm{~km}$ can reach values of 0.8 in presence of higher thermal contrasts. The DT/NT differences drive the sensitivity more than the land/sea underlying surface differences, especially for smaller and lower columns. The sensitivity of the surface$3 \mathrm{~km}$ TOC pseudo-observations, in terms of their DOFs, is about $20 \%$ better at DT than NT, and $11 \%$ better over land than over sea. Both differences are less important for the surface $-6 \mathrm{~km}$ TOC. The altitude of the maximum sensitivity of the surface $-3 \mathrm{~km}$ TOC is less affected by the difference of DT/NT and land/sea, than the DOF. Then, we have estimated the retrieval accuracy by comparing the pseudo-observations to the pseudo-reality. We have found average biases $<1 \%$ in magnitude, for the surface- $6 \mathrm{~km}$ TOC, and of about -2 to $-3 \%$, for the surface $-3 \mathrm{~km}$ TOC. The average RMSE is about $1.3 \mathrm{DU}(5 \%)$, for the surface- $6 \mathrm{~km}$ TOC, and about $1.5 \mathrm{DU}(10 \%)$, for the surface $-3 \mathrm{~km}$ TOC. The biases are mostly driven by the pixel surface type and the RMSEs by the observation hour. DT/NT performance are similar over sea but very different over land, with DT RMSEs smaller than 45 and $30 \%$, with respect to the NT subset, for the surface$6 \mathrm{~km}$ and surface $-3 \mathrm{~km}$ columns, respectively. The average RMSEs for the DT/land subset are about 0.9 DU (4\%) and $1.2 \mathrm{DU}(9 \%)$, for the two columns.

Then, we have tested the performance of MAGEAQ-TIR at some selected urban and rural locations. We have selected six very small regions $\left(0.2^{\circ} \times 0.2^{\circ}\right)$, representative of Milan (Italy), Paris (France), Berlin (Germany), Amsterdam (the Netherlands), one marine location west of Norway's coast $\left(55^{\circ} \mathrm{N}, 8^{\circ} \mathrm{E}\right)$, and Barcelona (Spain). We have investigated how MAGEAQ-TIR would be able to detect the vertical structures of typical phenomena occurring in 
the troposphere, and then we studied the time evolutions of the surface- $6 \mathrm{~km}$ and surface- $3 \mathrm{~km}$ TOCs. We have found that our MAGEAQ-TIR pseudo-observations can replicate the MOCAGE pseudo-reality variability at all altitudes, except at the surface- $1 \mathrm{~km}$ interval. The underestimations of surface ozone variability range from 55 to $87 \%$, with more severe underestimations at southern European locations. The small variability of the MAGEAQ-TIR concentration pseudo-observations at the lowest layers is attributable to a limited sensitivity at those altitudes. By studying the time series of the profile pseudo-observations, we have found that MAGEAQ-TIR's synthetic observations can partially describe the complex daily and weekly cycles at polluted urban sites. It seems that our MAGEAQ-TIR pseudo-observations have the potential to partly detect the photochemistry signal at the lowest altitudes, but the information content is redistributed and spread to higher altitudes. This signal seems generally very well detected in the column's time series of northern European urban locations. In any case, we observe artifacts in the column's time series, especially for the surface- $3 \mathrm{~km}$ TOC, at southern European urban locations. At Milan, for example, a marked daily cycle of the MOCAGE TOC pseudo-reality with a maximum at about 15:00 UTC is observed. At the same time, the sensitivity of the MAGEAQ-TIR pseudo-observations, in terms of the DOF, shows a marked cycle with up to $100 \%$ differences between maximum and minimum, with the maximum occurring at 12:00 UTC. In fact, at southern European urban location, the MAGEAQ-TIR sensitivity is mostly driven by the thermal contrast. The result is that the MAGEAQ-TIR column pseudo-observations, in particular for the surface$3 \mathrm{~km}$ TOCs, show an artifact maximum shifted back by several hours with respect to the target pseudo-reality. This artifact is sometimes observed also at Barcelona, so we argue that it is important where the sensitivity of the observations are more strongly driven by the thermal contrast. Other kind of phenomena occurring at altitudes lower than $2 \mathrm{~km}$, like the transport pattern of 20 August 2009 at a marine location, are not detected on a height-resolved basis. However, even if the vertical structure of these transport phenomena is missed at all sites, its signal can still be seen on the surface- $6 \mathrm{~km}$ and surface- $3 \mathrm{~km}$ columns, at some locations. MAGEAQTIR seems capable of detecting the vertical structures of phenomena occurring at altitudes higher than $2 \mathrm{~km}$, like deep STEs, even if characterised by particularly short time evolutions (of the order of 1 day). In summary, while the vertical structures of the lowermost tropospheric ozone pseudoreality are sometimes missed or spread onto larger vertical intervals, MAGEAQ-TIR column pseudo-observations follow stunningly well the MOCAGE column pseudo-reality. For the comparison of MAGEAQ-TIR and MOCAGE TOCs, very high correlation coefficients (0.93-0.97 and 0.83-0.91), low biases $(<1.6$ and $<5.0 \%$, in magnitude) and low RMSEs (4.20-4.60\% and 8.9-9.8\%) are found for the surface$6 \mathrm{~km}$ and the surface- $3 \mathrm{~km}$ TOCs, at northern European urban locations and at the marine location. A worse performance is found at southern European locations, e.g. at Milan, with correlations of 0.82 and 0.55 , biases of 4.2 and $10.8 \%$, RMSEs of 6.4 and $13.5 \%$, for the surface- $6 \mathrm{~km}$ and the surface- $3 \mathrm{~km}$ TOCs.

These analyses, although pointing out the limitations of an AQ-dedicated GEO instrument like MAGEAQ-TIR, show that it would be a great step forward to gain a more solid monitoring capability of short-term pollution phenomena at the local and continental scale in Europe. A future step would be the performance analysis of a multi-spectral approach, e.g. by including in our analyses the VIS component of MAGEAQ and/or MTG-UVN observations.

Acknowledgements. The authors are grateful to CNRS-INSU for publication support. This work is carried on in the framework of the CNES/TOSCA/GeoQAir (quantification de l'apport d'une plateforme d'observations GÉOstationnaires pour la surveillance de la Qualité de l'AIR). We wish to thank the Institut für Meteorologie und Klimaforschung (IMK), Karlsruhe Institute of Technology (KIT), Germany, for a licence to use KOPRA radiative transfer model. The authors acknowledge the use of resources provided by the European Grid Infrastructure. For more information, please reference the EGI-InSPIRE paper (http://go.egi.eu/pdnon). MOCAGE data have been provided by Météo France. The three anonymous referees are gratefully acknowledged for their constructive criticism.

Edited by: T. von Clarmann

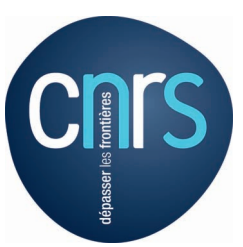

The publication of this article is financed by CNRS-INSU.

\section{References}

Amann, M., Bertok, I., Cofala, J., Gyarfas, F., Heyes, C., Klimont, Z., Schöpp, W., and Winiwarter, W.: Baseline scenarios for the Clean Air For Europe (CAFE) programme, Tech. rep., International Institute for Applied Systems Analysis, for the European Commission Directorate General for Environment, Directorate C: Environment and Health, 2005.

Atmospheric Composition Constellation: A geostationary satellite constellation for observing global air quality: An international path forward, Tech. rep., Committee on Earth Observation Satellites (CEOS), 2011.

Bazalgette Courrèges-Lacoste, G., Ahlers, B., Guldimann, B., Short, A., Veihelmann, B., and Stark, H.: The Sentinel-4/UVN instrument on-board MTG-S, in: EUMETSAT Meteorological Satellite Conference, Oslo, Norway, 2011.

Bousserez, N., Attié, J. L., Peuch, V. H., Michou, M., Pfister, G., Edwards, D., Emmons, L., Mari, C., Barret, B., Arnold, S. R., Heckel, A., Richter, A., Schlager, H., Lewis, A., Avery, M., Sachse, G., Browell, E. V., and Hair, J. W.: Eval- 
uation of the MOCAGE chemistry transport model during the ICARTT/ITOP experiment, J. Geophys. Res.-Atmos., 112, D10S42, doi:10.1029/2006JD007595, 2007.

Bowman, K. W., Rodgers, C. D., Kulawik, S. S., Worden, J., Sarkissian, E., Osterman, G., Steck, T., Lou, M., Eldering, A., Shephard, M. W., Worden, H. M., Lampel, M., Clough, S. A., Brown, P., Rinsland, C. P., Gunson, M. R., and Beer, R.: Tropospheric emission spectrometer: retrieval method and error analysis, IEEE T. Geosci. Remote Sens., 44, 1297-1307, doi:10.1109/TGRS.2006.871234, 2006.

Boynard, A., Clerbaux, C., Coheur, P.-F., Hurtmans, D., Turquety, S., George, M., Hadji-Lazaro, J., Keim, C., and MeyerArnek, J.: Measurements of total and tropospheric ozone from IASI: comparison with correlative satellite, ground-based and ozonesonde observations, Atmos. Chem. Phys., 9, 6255-6271, doi:10.5194/acp-9-6255-2009, 2009.

Burrows, J., Bovensmann, H., Bergametti, G., Flaud, J., Orphal, J., Noël, S., Monks, P., Corlett, G., Goede, A., von Clarmann, T., Steck, T., Fischer, H., and Friedl-Vallon, F.: The geostationary tropospheric pollution explorer (GeoTROPE) mission: objectives, requirements and mission concept, Adv. Space Res., 34, 682-687, doi:10.1016/j.asr.2003.08.067, 2004.

Claeyman, M., Attié, J.-L., Peuch, V.-H., El Amraoui, L., Lahoz, W. A., Josse, B., Joly, M., Barré, J., Ricaud, P., Massart, S., Piacentini, A., von Clarmann, T., Höpfner, M., Orphal, J., Flaud, J.M., and Edwards, D. P.: A thermal infrared instrument onboard a geostationary platform for $\mathrm{CO}$ and $\mathrm{O}_{3}$ measurements in the lowermost troposphere: Observing System Simulation Experiments (OSSE), Atmos. Meas. Tech., 4, 1637-1661, doi:10.5194/amt-41637-2011, 2011a.

Claeyman, M., Attié, J.-L., Peuch, V.-H., El Amraoui, L., Lahoz, W. A., Josse, B., Ricaud, P., von Clarmann, T., Höpfner, M., Orphal, J., Flaud, J.-M., Edwards, D. P., Chance, K., Liu, X., Pasternak, F., and Cantié, R.: A geostationary thermal infrared sensor to monitor the lowermost troposphere: $\mathrm{O}_{3}$ and $\mathrm{CO}$ retrieval studies, Atmos. Meas. Tech., 4, 297-317, doi:10.5194/amt-4-297-2011, 2011 b.

Cuesta, J., Eremenko, M., Liu, X., Dufour, G., Cai, Z., Höpfner, M., von Clarmann, T., Sellitto, P., Foret, G., Gaubert, B., Beekmann, M., Orphal, J., Chance, K., Spurr, R., and Flaud, J.-M.: Satellite observation of lowermost tropospheric ozone by multispectral synergism of IASI thermal infrared and GOME-2 ultraviolet measurements over Europe, Atmos. Chem. Phys., 13, 9675-9693, doi:10.5194/acp-13-9675-2013, 2013.

Derwent, R., Jenkin, M., and Saunders, S.: Photochemical ozone creation potentials for a large number of reactive hydrocarbons under European conditions, Atmos. Environ., 30, 181-199, doi:10.1016/1352-2310(95)00303-G, 1996.

Di Noia, A., Sellitto, P., Del Frate, F., and de Laat, J.: Global tropospheric ozone column retrievals from OMI data by means of neural networks, Atmos. Meas. Tech., 6, 895-915, doi:10.5194/amt6-895-2013, 2013.

Dufour, A., Amodei, M., Ancellet, G., and Peuch, V.-H.: Observed and modelled "chemical weather" during ESCOMPTE, Atmos. Res., 74, 161-189, doi:10.1016/j.atmosres.2004.04.013, 2005.

Dufour, G., Eremenko, M., Orphal, J., and Flaud, J.-M.: IASI observations of seasonal and day-to-day variations of tropospheric ozone over three highly populated areas of China: Bei- jing, Shanghai, and Hong Kong, Atmos. Chem. Phys., 10, 37873801, doi:10.5194/acp-10-3787-2010, 2010.

Dufour, G., Eremenko, M., Griesfeller, A., Barret, B., LeFlochmoën, E., Clerbaux, C., Hadji-Lazaro, J., Coheur, P.-F., and Hurtmans, D.: Validation of three different scientific ozone products retrieved from IASI spectra using ozonesondes, Atmos. Meas. Tech., 5, 611-630, doi:10.5194/amt-5-611-2012, 2012.

Eremenko, M., Dufour, G., Foret, G., Keim, C., Orphal, J., Beekmann, M., Bergametti, G., and Flaud, J.-M.: Tropospheric ozone distributions over Europe during the heat wave in July 2007 observed from infrared nadir spectra recorded by IASI, Geophys. Res. Lett., 35, L18805, doi:10.1029/2008GL034803, 2008.

Eremenko, M., Weissenbach, D., Sellitto, P., Cuesta, J., Forêt, G., and Dufour, G.: GeoQAIR: quantification de l'apport d'une plateforme satellitaire d'observations Géostationnaires pour la surveillance de la Qualité de l'AIR en Europe, in: Proceedings of Journées scientifiques mésocentres et France Grilles, available at: http://mesogrilles2012.sciencesconf.org/8556/document (last access: 4 February 2014), 2012.

Fishman, J. and Larsen, J. C.: Distribution of total ozone and stratospheric ozone in the tropics: Implications for the distribution of tropospheric ozone, J. Geophys. Res., 92, 6627-6634, 1987.

Fishman, J., Iraci, L. T., Al-Saadi, J., Chance, K., Chavez, F., Chin, M., Coble, P., Davis, C., DiGiacomo, P. M., Edwards, D., Eldering, A., Goes, J., Herman, J., Hu, C., Jacob, D. J., Jordan, C., Kawa, S. R., Key, R., Liu, X., Lohrenz, S., Mannino, A., Natraj, V., Neil, D., Neu, J., Newchurch, M., Pickering, K., Salisbury, J., Sosik, H., Subramaniam, A., Tzortziou, M., Wang, J., and Wang, M.: The United States' next generation of atmospheric composition and coastal ecosystem measurements: NASA's Geostationary Coastal and Air Pollution Events (Geo-Cape) Mission, B. Am. Meteorol. Soc., 93, 1547-1566, doi:10.1175/BAMS-D-11$00201.1,2012$.

Flaud, J.-M., Orphal, J., Bergametti, G., Deniel, C., von Clarmann, T., Friedl-Vallon, F., Steck, T., Fischer, H., Bovensmann, H., Burrows, J., Carlotti, M., Ridolfi, M., and Palchetti, L.: The Geostationary Fourier Imaging Spectrometer (GeoFIS) as part of the Geostationary Tropospheric Pollution Explorer (GeoTroPE) mission: objectives and capabilities, Adv. Space Res., 34, 688-693, doi:10.1016/j.asr.2003.07.072, 2004.

Forêt, G., Eremenko, M., Sellitto, P., Barré, J., Gaubert, B., Coman, A., Cuesta, J., Dufour, G., and Beekmann, M.: Ozone pollution: What do we see from space? A case study, in: IASI Conference (Hyeres, France), 2013.

Fu, D., Worden, J. R., Liu, X., Kulawik, S. S., Bowman, K. W., and Natraj, V.: Characterization of ozone profiles derived from Aura TES and OMI radiances, Atmos. Chem. Phys., 13, 3445-3462, doi:10.5194/acp-13-3445-2013, 2013.

Fuglestved, J., Jonson, J., and Isaksen, I.: Effects of reductions in stratospheric ozone on tropospheric chemistry through changes in photolysis rates, Tellus B, 46, 3, doi:10.1034/j.16000889.1992.t01-3-00001.x-i1, 2011.

Hoepfner, M., Blom, C. E., Echle, G., Glatthor, N., Hase, F., and Stiller, G.: Retrieval simulations for MIPAS-STR measurements, in: IRS 2000: Current Problems in Atmospheric Radiation; Proceedings of the International Radiation Symposium, edited by: Smith, W. L., Deepak, 2001. 
Hsu, J. and Prather, M. J.: Stratospheric variability and tropospheric ozone, J. Geophys. Res.-Atmos., 114, D06102, doi:10.1029/2008JD010942, 2009.

Lahoz, W. A., Peuch, V.-H., Orphal, J., Attié, J.-L., Chance, K., Liu, X., Edwards, D., Elbern, H., Flaud, J.-M., Claeyman, M., and El Amraoui, L.: Monitoring air quality from space: the case for the geostationary platform, B. Am. Meteorol. Soc. 93, 221-233, doi:10.1175/BAMS-D-11-00045.1, 2012.

Lefèvre, F., Brasseur, G. P., Folkins, I., Smith, A. K., and Simon, P.: Chemistry of the 1991-1992 stratospheric winter: three dimensional model simulations, J. Geophys. Res., 99, 8183-8195, 1994.

Liu, X., Chance, K., Sioris, C. E., Spurr, R. J. D., Kurosu, T. P., Martin, R. V., and Newchurch, M. J.: Ozone profile and tropospheric ozone retrieval from Global Ozone Monitoring Experiment (GOME): Algorithm description and validation, J. Geophys. Res., 110, D20307, doi:10.1029/2005JD006240, 2005.

Liu, X., Bhartia, P. K., Chance, K., Spurr, R. J. D., and Kurosu, T. P.: Ozone profile retrievals from the Ozone Monitoring Instrument, Atmos. Chem. Phys., 10, 2521-2537, doi:10.5194/acp-10-25212010, 2010.

Martin, V. R.: Satellite remote sensing of surface air quality, Atmos. Environ., 42, 7823-7843, doi:10.1016/j.atmosenv.2008.07.018, 2008.

McPeters, R. D., Labow, G. J., and Logan, J. A.: Ozone climatological profiles for satellite retrieval algorithms, J. Geophys. Res., 112, D05308, doi:10.1029/2005JD006823, 2007.

Munro, R., Siddans, R., Reburn, W. J., and Kerridge, B. J.: Direct measurement of tropospheric ozone distributions from space, Nature, 392, 171-198, 1998.

Natraj, V., Liu, X., Kulawik, S., Chance, K., Chatfield, R., Edwards, D. P., Eldering, A., Francis, G., Kurosu, T., Pickering, K., Spurr, R., and Worden, H.: Multi-spectral sensitivity studies for the retrieval of tropospheric and lowermost tropospheric ozone from simulated clear-sky GEO-CAPE measurements, Atmos. Environ., 45, 7151-7165, doi:10.1016/j.atmosenv.2011.09.014, 2011.

Osterman, G. B., Kulawik, S. S., Worden, H. M., Richards, N. A. D., Fisher, B. M., Eldering, A., Shephard, M. W., Froidevaux, L., Labow, G., Luo, M., Herman, R. L., Bowman, K. W., and Thompson, A. M.: Validation of Tropospheric Emission Spectrometer (TES) measurements of the total, stratospheric, and tropospheric column abundance of ozone, J. Geophys. Res.-Atmos., 113, D15S16, doi:10.1029/2007JD008801, 2008.

Peuch, V.-H., Orphal, J., Attié, J.-L., Chance, K. V., Liu, X., Edwards, D., Elbern, H., Flaud, J.-M., Lahoz, W., Beekmann, M., Bergametti, G., Dufour, G., Eremenko, M., Brasseur, G., Buchmann, B., Builtjes, P., Carlotti, M., Ridolfi, M., Claeyman, M., Ricaud, P., von Clarmann, T., Höpfner, M., Vogel, B., Dudhia, A., El Amraoui, L., Joly, L., Josse, B., Eldering, A., Funke, B., Hov, Ø., Jacob, D., Kasai, Y., Kurosu, T. P., Lelieveld, J., Lawrence, M., Macke, A., de Maziére, M., Ménard, R., Menut, L., Palmer, P., Poisson, R., Rouïl, L., Saiz-Lopez, A., Tanre, F., Warner, J., Cantié, R., Desmaziéres, Y., Maliet, E., and Pasternak, F.: MAGEAQ - Monitoring the Atmosphere from Geostationary orbit for European Air Quality: A candidate for Earth Explorer Opportunity Mission EE-8, Tech. rep., 2010.

Rodgers, C. D.: Characterization and Error Analysis of Profiles Retrieved from Remote Sounding Instruments, J. Geophys. Res., 95, 5587-5595, doi:10.1029/JD095iD05p05587, 1990.
Schoeberl, M. R., Ziemke, J. R., Bojkov, B., Livesey, N., Duncan, B., Strahan, S., Froidevaux, L., Kulawik, S., Bhartia, P. K., Chandra, S., Levelt, P. F., Witte, J. C., Thompson, A. M., Cuevas, E., Redondas, A., Tarasick, D. W., Davies, J., Bodeker, G., Hansen, G., Johnson, B. J., Oltmans, S. J., Vömel, H., Allaart, M., Kelder, H., Newchurch, M., Godin-Beekmann, S., Ancellet, G., Claude, H., Andersen, S. B., Kyrö, E., Parrondos, M., Yela, M., Zablocki, G., Moore, D., Dier, H., von der Gathen, P., Viatte, P., Stübi, R., Calpini, B., Skrivankova, P., Dorokhov, V., de Backer, H., Schmidlin, F. J., Coetzee, G., Fujiwara, M., Thouret, V., Posny, F., Morris, G., Merrill, J., Leong, C. P., Koenig-Langlo, G., and Joseph, E.: A trajectory-based estimate of the tropospheric ozone column using the residual method, J. Geophys. Res., 112, D24S49, doi:10.1029/2007JD008773, 2007.

Sellitto, P., Bojkov, B. R., Liu, X., Chance, K., and Del Frate, F.: Tropospheric ozone column retrieval at northern mid-latitudes from the Ozone Monitoring Instrument by means of a neural network algorithm, Atmos. Meas. Tech., 4, 2375-2388, doi:10.5194/amt-4-2375-2011, 2011.

Sellitto, P., Del Frate, F., Solimini, D., and Casadio, S.: Tropospheric ozone column retrieval from ESA-Envisat SCIAMACHY nadir UV/VIS radiance measurements by means of a neural network algorithm, IEEE T. Geosci. Remote, 50, 9981011, doi:10.1109/TGRS.2011.2163198, 2012a.

Sellitto, P., Noia, A. D., Frate, F. D., Burini, A., Casadio, S., and Solimini, D.: On the role of visible radiation in ozone profile retrieval from nadir UV/VIS satellite measurements: an experiment with neural network algorithms inverting SCIAMACHY data, J. Quant. Spectrosc. Ra., 113, 1429-1436, doi:10.1016/j.jqsrt.2012.04.007, 2012b.

Sellitto, P., Dufour, G., Eremenko, M., Cuesta, J., Dauphin, P., Forẽt, G., Gaubert, B., Beekmann, M., Peuch, V.-H., and Flaud, J.-M.: Analysis of the potential of one possible instrumental configuration of the next generation of IASI instruments to monitor lower tropospheric ozone, Atmos. Meas. Tech., 6, 621-635, doi:10.5194/amt-6-621-2013, 2013a.

Sellitto, P., Dufour, G., Eremenko, M., Cuesta, J., Peuch, V.-H., Eldering, A., Edwards, D. P., and Flaud, J.-M.: The effect of using limited scene-dependent averaging kernels approximations for the implementation of fast observing system simulation experiments targeted on lower tropospheric ozone, Atmos. Meas. Tech., 6, 1869-1881, doi:10.5194/amt-6-1869-2013, 2013b.

Shindell, D. T., Faluvegi, G., Koch, D. M., Schmidt, G. A., Unger, N., and Bauer, S. E.: Improved Attribution of Climate Forcing to Emissions, Science, 326, 716-718, doi:10.1126/science.1174760, 2009.

Stiller, G. P., von Clarmann, T., Funke, B., Glatthor, N., Hase, F., Höpfner, M., and Linden, A.: Sensitivity of trace gas abundances retrievals from infrared limb emission spectra to simplifying approximations in radiative transfer modelling, J. Quant. Spectrosc. Ra., 72, 249-280, doi:10.1016/S0022-4073(01)00123-6, 2002.

Stockwell, W. R., Kirchner, F., Khun, M., and Seefeld, S.: A new mechanism for regional atmospheric chemistry modelling, J. Geophys. Res., 102, 25847-25879, 1997.

Stuhlmann, R., Rodriguez, A., Tjemkes, S., Grandell, J., Arriaga, A., Bézy, J.-L., Aminou, D., and Bensi, P.: Plans for EUMETSAT's Third Generation Meteosat (MTG) geostationary satellite program, Adv. Space Res., 36, 975-981, 2005. 
The Integrated Global Atmospheric Chemistry Observation Theme Team: The changing atmosphere: an integrated global atmospheric chemistry observation theme for the IGOS partnership, Tech. rep., Global Atmospheric Watch, Geneva, Switzerland, available at: ftp://ftp.wmo.int/Documents/PublicWeb/arep/gaw/ gaw159.pdf (last access: 4 February 2014), 2004.

WMO: Scientific assessment of ozone depletion: 2006, Executive Summary, 2007.

Worden, H. M., Logan, J. A., Worden, J. R., Beer, R., Bowman, K., Clough, S. A., Eldering, A., Fisher, B. M., Gunson, M. R., Herman, R. L., Kulawik, S. S., Lampel, M. C., Luo, M., Magretskaia, I. A., Osterman, G. B., and Shephard, M. W.: Comparisons of Tropospheric Emission Spectrometer (TES) ozone profiles to ozonesondes: Methods and initial results, J. Geophys. Res., 112, D03309, doi:10.1029/2006JD007258, 2007a.
Worden, J., Liu, X., Bowman, K., Chance, K., Beer, R., Eldering, A., Gunson, M., and Worden, H.: Improved tropospheric ozone profile retrievals using OMI and TES radiances, Geophys. Res. Lett., 34, L01809, doi:10.1029/2006GL027806, $2007 \mathrm{~b}$.

Ziemke, J. R., Chandra, S., and Bhartia, P. K.: Upper tropospheric ozone derived from the cloud slicing technique: Implications for large-scale convection, J. Geophys. Res., 108, 4390, doi:10.1029/2002JD002919, 2003. 